\title{
UNDERSTANDING WELLNESS FOR YOUNG ADULTS THROUGH INSTAGRAM INFLUENCERS' CONTENT
}

A Thesis
presented to
the Faculty of the Graduate School
at the University of Missouri-Columbia
In Partial Fulfillment
of the Requirements for the Degree
Master of Journalism
Professor Jeannette Porter, Thesis Supervisor
MAY 2021


UNDERSTANDING WELLNESS

The undersigned, appointed by the dean of the Graduate School, have examined the thesis entitled

\section{UNDERSTANDING WELLNESS FOR YOUNG ADULTS THROUGH INSTAGRAM INFLUENCERS' CONTENT}

presented by Gina Gerstenecker, a candidate for the degree of master of journalism and hereby certify that, in their opinion, it is worthy of acceptance.

Professor Jeannette Porter

Professor Jon Stemmle

Professor Jamie Flink 


\section{ACKNOWLEDGEMENTS}

I would like to thank Professor Porter for encouraging my idea and for supporting me in every step of the process. This thesis could not have gotten off the ground without her or her guidance and for that I thank her.

I would also like to thank Professor Stemmle for stepping in to assist the completion of this research. His unwavering support and enthusiasm for this project did not go unnoticed.

It was my goal to choose members of the faculty who be knowledgable and interested in my topic. I did not expect the immense amount of encouragement I received from all three of the members of my committee: Jeannette Porter, Jon Stemmle, and Jamie Flink. While Porter and Stemmle both assisted in the creation and execution of this research project, Flink proved to be one of my largest supporters during this process. I sincerely thank each and every one of my professors for their help, and I thank Jamie Flink specifically for her loving guidance during my final year. 


\section{DEDICATION}

I would like to dedicate this thesis to my parents, Michelle and Leroy Gerstenecker. They were the ones who always taught me that, although education does not define you, if you hold your head high and stand up straight you can accomplish anything. This master's thesis is the culmination of all the unspoken lessons I have learned from them about hard work, loyalty and dedication. I am truly blessed to have them as parents, and I will always be grateful for the lesson the rest of my family taught me: to always set a good example in life because little eyes are always watching.

Love always, your punkin. 


\section{TABLE OF CONTENTS}

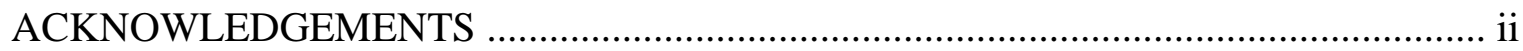

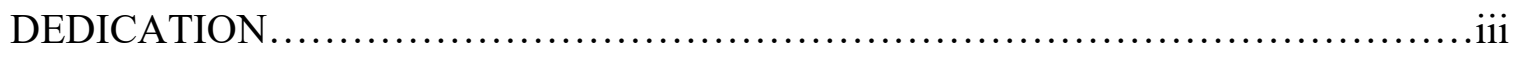

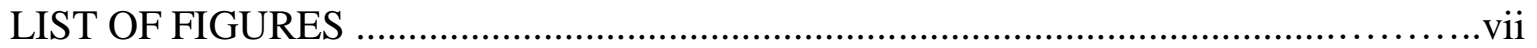

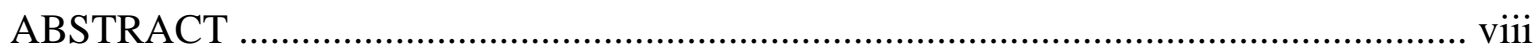

Chapter

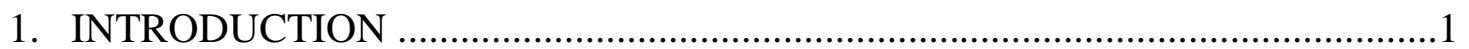

Research Problem

Method

Purpose Statement

Explication of Concepts

Wellness

Influencer Marketing

Introduction Summary

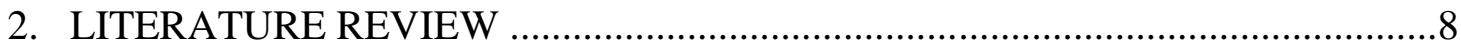

Self-Presentation Theory

Lifestyle Influencers

Young-Adult Audience

Research Questions

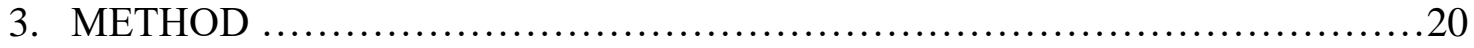

Research Materials

Coding

Steps 
Data Analysis

Textual Analysis

Photographic Analysis

Method Choice

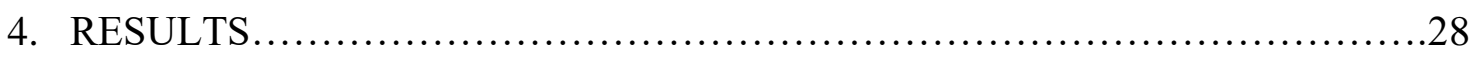

Word Usage

Common Themes

Hashtags

Branded Content

Accounts Tagged

Textual Tone

Photo Content

Results Conclusion

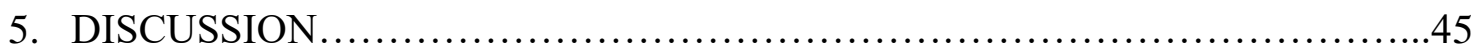

RQ1

RQ1a

RQ2

Limitations and Areas for Further Research

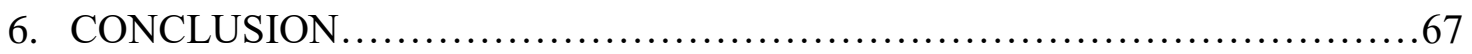

\section{APPENDIX}

1. INFLUENCER LIST.

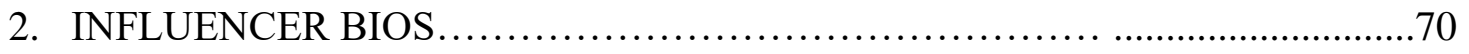

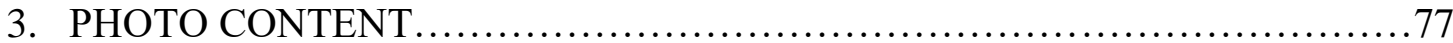




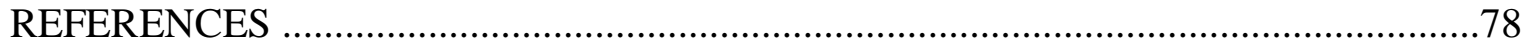




\section{LIST OF FIGURES}

Figure:

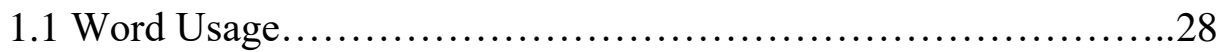

1.2 Common Themes................................................... 30

1.3 Hashtags ..................................................... 32

1.4 Branded Content............................................... 34

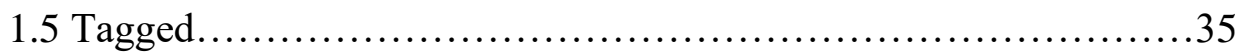

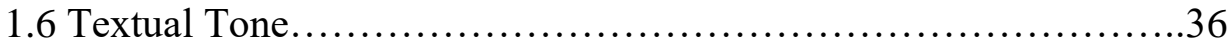

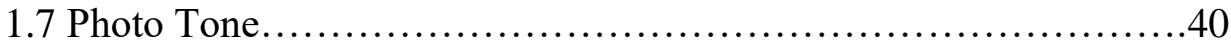




\title{
UNDERSTANDING WELLNESS FOR YOUNG ADULTS THROUGH INSTAGRAM INFLUENCERS' CONTENT
}

\author{
Gina Gerstenecker
}

Professor Jeannette Porter, Thesis Supervisor

\begin{abstract}
Wellness has become an increasingly popular trend for young adults that brands and advertisers have been trying to keep up with. Wellness has taken on a muddled meaning with each product marketing different wellness properties that contribute to a person's holistic health. Drawing on self-presentation theory, this thesis examined the self-presentation of 15 lifestyle Instagram influencers who claim to specialize in wellness. This was accomplished through a content analysis analyzing both textual and photographic content of ten posts from each influencer. A total of 150 posts including 247 photos were analyzed during this study. Results revealed that wellness was a confusing and frustrating topic, and many turned to influencers to be their guide throughout this wellness journey. Overall, wellness journeys aim to end in individual happiness and living "well" means to feel happy and healthy.

Keywords: wellness, health, self-care, well-being, influencer, Instagram, self-presentation theory
\end{abstract}




\section{Chapter 1: Introduction}

According to Mintel, the world's leading marketing intelligence agency, and their report on Global Consumer Trends (2020b), the idea of "wellness" is around to stay. Mintel lists "wellbeing" as one of its core trend drivers that will motivate consumer decisions over the next 10 years. They cite well-being as "seeking physical and mental wellness" (Mintel, 2020b). This practice of seeking wellness manifests in consumer behavior as an incresing number of individuals question the holistic well-being-benefit of every product even down to the last ingredient.

According to Cavusoglu and Demirbag-Kaplan (2017), the internet has put an abundance of information at our fingertips, and the public is turning to digital media to redefine what it means to be healthy. Cavusoglu and Demirbag-Kaplan state that the media is playing a central role in individuals taking it upon themselves to maintain their well-being to prevent trips to the doctor. In the digital age, Cavusoglu and Demirbag-Kaplan group individualized health around four different categories: food, fashion, fitness, and feelings (Cavusoglu \& Demirbag-Kaplan, 2017). Naturally, these categories have been flooded by wellness products claiming to better the body and mind and are associated with a commodification of the wellness trend.

\section{Research Problem}

The problem lies in the fact that wellness is broadly defined and does not seem to have a standard, individual definition (Cederstom \& Spicer, 2015). It is often interchanged with words and phrases such as self-care, health, or well-being. The term can also be applied to any area of the self, resulting in brands marketing wellness products ranging from detox teas and face masks to elliptical machines. According to Mintel (2020b), many young adults will begin to seek out 
wellness products since stressors from an unforeseen global pandemic have harmed their physical, emotional, and mental health. Further research will need a working understanding of the word in which these young adults invest their well-being.

\section{Method}

I conducted a content analysis on 15 wellness-lifestyle Instagram influencers' content which appeals to the 18-to-24-year-old age range. My research focused on analyzing both textual and photographic content to determine how wellness influencers self-present themselves and their lifestyles to their audience. I selected 10 posts from each influencer, five of the most recent posts after December 11 and five posts made six months prior to account for seasonality. Each influencer's content was first analyzed separately and then together to determine commonalities across all of the influencers' content. Through these commonalities, an understanding of wellness from a young adult wellness-influencer's point-of-view was created.

According to Mintel's report on Internet Influencers (2020a), 79\% of 18-24-year-olds say it is important that who they follow on social media represents their views and $54 \%$ feel personally connected to the internet celebrities they follow. A study from Geometry Global and gen.video (2017) also states that Instagram, a popular photo-based social media site, and YouTube, a popular video-based social media site, are the most trusted platforms for influencers, with YouTube only slipping when a product demonstration was not needed. Today, Instagram and TikTok, another popular short video-based social media site, are the most popular platforms for Generation $\mathrm{Z}$ and both platforms have a heavy influencer presence (Haenlein, 2020). However, since TikTok began in 2016, there has been less scholarly data about the platform. Upon extensive literature research, it is clear that there is more concrete evidence supporting Instagram as an influencer platform that users trust. An influencer's perspective guides how 
these young adults perceive wellness, and this research led me to determine what 18-to-24-yearolds value in their life when it comes to "wellness." I studied these influencers' content to determine how they presented the concept of wellness to their audience through their organic and paid online self-presentation.

Self-presentation theory, developed by Erving Goffman in 1959, guided this study. Goffman relates the theory to an actor on stage who will perform a role to please the audience. Based on Baumeister and Hutton's interpretation of self-presentation theory (1987), these influencers should present themselves consistently with their audience's preferences. Because an influencer's audience indicates success or failure through two-way communication of likes, follows, and comments, the influencer has reflected the audience's views to gain trust and acceptance. In this case, they are reflecting their audience's preferences on wellness since they are deliberately seeking their audience's agreement in their self-appointed status as wellness influencers. According to theory, the audience is also presenting that they agree with this influencer's lifestyle by digitally interacting with them and their products through likes. For instance, according to Mintel's Internet Influencers report (2020a), 73\% of young adults aged 18-24 typically engage with social media personalities by liking their posts.

\section{Purpose Statement}

The purpose of this research was to come to an understanding of how influencers present the concept of wellness to their young adult audience. The importance of this study stretches across many disciplines guiding future researchers, economists and inventors as they embark on new wellness creations. Young adults' growing perceptions of wellness are being shaped by the influncers they follow and engage with. It is important to the advertising industry to understand how these individuals perceive wellness in order to create relevant messaging for brands 
targeting that demographic. Allowing brands to know what consumers are looking for in wellness can help those brands fill an unmet need in the lives of their consumers. An understanding of wellness can also aid in the regulation of potentially dangerous "wellness" products intended for use inside or outside of the body. Currently, states are unable to regulate the selling of "wellness" products because they are not directly related to health. Aside from advertising and product creation, this study is still important in an even broader sense and could help the psychology and sociology realms understand what young adults are wanting to improve in their lives and could lead to a more tailored approach to wellness that meets consumers' specific needs.

\section{Explication of Concepts}

Since wellness can be broadly defined, it is often mentioned alongside studies related to self-care, wellbeing, and health (Cavusoglu \& Demirbag-Kaplan, 2017; Mintel, 2020b; Lieberman, 2018). For this literature review, self-care, health, wellbeing, and wellness studies will be cited as long as they regard the holistic practice of caring for oneself. Upon review of the literature, these terms consistently surfaced in conjunction with the term "wellness." I started with a broad definition of wellness meaning anything that an individual can do to better themselves physically, emotionally, and/or mentally.

\section{Wellness}

Self-care and wellness are not new phenomena. According to French philosopher Michael Foucault (2020), "care of the self” has been a practice since the Hellenistic and Roman Periods. Philosophers like Plato, Seneca, Plutarch, and Epictetus advised an individual to step away from political speech and focus on knowing oneself because care of the self was one of the most important keys to individual success. The Ancient Egyptians documented their cosmetic 
routines as self-care rituals and often left these items in their tombs for use in the afterlife. They used beauty products to shield their skin from harsh elements and the Egyptian word for "makeup palette" derives from their word meaning "protect," (Wolkoff, 2020). Roman self-care was centered around relaxation techniques, and the Romans were particularly famous for their baths which they used for both hygiene and relaxation (Cartwright, 2013). Confucianism, Taoism and Buddhism all emphasize spirituality and self-fostered serenity, and they are considered to be the three pillars of ancient Chinese society (National Geographic Society, 2019). Today, wellness writers turn to these ancient rituals as a guideline for modern wellbeing (Sweet, 2018).

The modern self-improvement market, defined by Lieberman as anything to improve an individual's well-being, has grown to become an \$11 billion industry (Lieberman, 2018). Guided meditations, wearable fitness devices, and Instagram influencers peddling scented candles and bubble baths have become necessities in the eyes of the self-care-conscious consumer. Lieberman (2018) writes that some products may not even improve individuals, but instead fill them with guilt if they do not meet their ideals or goals for the day. Regardless of whether or not these products better the self, people buy them because they believe they are taking steps to selfimprovement, a pursuit very much part of today's globalized and competitive society.

\section{Influencer Marketing}

Mintel's Internet Influencers Report (2020a) defines influencers as those who have a following on social media outside of their personal network. The same report states that brands have increasingly turned to influencers on social media for marketing promotion and collaboration of consumer products. 
Typically, where there is an area for brand growth and profit, advertising is present. Thorson and Rodgers (2019) define advertising as "brand initiated content intent on impacting people," (p. 203). They say, in the digital age, advertising messages are often created and promoted by ordinary individuals rather than a brand or company. This user-generated content can include paid or unpaid sponsorships.

According to Thorson and Rodgers (2019), advertising clutter can lead to resistance to advertising messages. In strategic communication, advertising clutter refers to the growing number of advertisements an individual is exposed to in a single day. When an individual is exposed to growing amounts of advertisements, the individual experiences fatigue and learns to block out the ads. Thus, more creative forms of advertising need to be employed to break through the clutter. Miller and Levine (2019) state that the emotions created by the type of content being consumed can affect how the individual feels about the ad. They add that attitudes are highly correlated to behaviors. Putting these together, advertisers are striving to create a seamless ad experience that positively affects the consumer's attitude. According to Mintel's study on Internet Influencers (2020a), influencer marketing has risen in popularity to get consumers more engaged with brands' content. Mintel defines influencer marketing as the promotion of products or services via social media personalities. These social media personalities are dubbed "influencers" and are paid by media companies to promote specific products on sponsored posts to their social media page.

Thorson and Rodgers (2019) assert that consumers are more likely to respond to advertising messaging when the content is congruent with the kind of media in which it is featured. For example, native advertising is created to blend seamlessly with other content so consumers will be less likely to skip over the advertising. According to Miller and Levine 
(2019), "We are more likely to be persuaded by sources we perceive to be powerful, in authority, attractive, likable, or similar to us than by sources we perceive as not possessing these traits," (p.262). This finally brings us to influencers. A popular type of influencer is a digital influencer, or social media mogul, with a large following who is paid to promote specific products and lifestyles. Influencers embody all of Miller and Levine's persuasion traits, and, according to Mintel, are listed as an advertising tactic that is working for Gen Z (born after 1996) (2020c).

\section{Introduction Summary}

Ultimately, this study will serve to understand wellness through the ways lifestyle Instagram influencers present their wellness content to young adults. Instagram was established in 2010, is now owned by Facebook, and emphasizes the pairing of text and images. The app has been consistently popular with Gen Z. If these influencers are successful in defining their audience, then their views should mirror what their consumers are looking for in wellness products. This will lead to a working definition of how young adults understand wellness. 


\section{Chapter 2: Literature Review}

This literature review will attempt to uncover the history behind the definite sections of this research including theory, influencer marketing, social media marketing, and wellness. This literature review will first discuss the history and meaning behind self-presentation theory. A segment of influencer and social media platform will then be identified as the most ideal data set for this research. Lastly, existing definitions of wellness will be examined to determine how broadly the term is applied in modern literature.

\section{Self-Presentation Theory}

Self-Presentation Theory was developed by Erving Goffman in 1959 as a way to explain how people present themselves to influence or manipulate an audience. Goffman relates selfpresentation to an actor performing on stage. The individual is likely to perform when in front of an audience during a group situation. This is done to prevent the audience from seeing "backstage" and only presents what the actor wants the public to see (Goffman, 1959).

Human interaction is shaped by interpersonal evaluations, so humans have evolved to present themselves in ways that reflect the group situation they are in so as not to be excluded from the group (Baumeister \& Hutton, 1987). Baumeister and Hutton (1987) define selfpresentation as "behavior that attempts to convey some information about oneself or some image of oneself to other people" (p. 71). They argue two types of self-presentation exist: one is for pleasing the audience, and the other is for self-construction. Self-construction presentation theory states that an individual will match their self-presentation to their ideal self. On the other hand, pleasing-the-audience self-presentation theory states that one will match their self-presentation to the audience's perceived expectations and preferences (Baumeister \& Hutton, 1987). Therefore, 
by studying the influencer's content, I will gain a deeper understanding of the ideals of these young consumers.

The pleasing-the-audience component of this theory has been especially useful when studying social media. Several scholars have used self-presentation theory to explain why social media influencers can be so persuasive. According to Jensen Schau and Gilly (2003), consumers use products to communicate and establish an ideal affirmative identity to assimilate themselves as a part of a group ideal. They say that products are one of the most important ways people can communicate with each other. Consumption serves as a way for individuals to express their ideal selves to others. For example, wearing a Fitbit device might mean staying healthy to those who use them, and those who wear them in public want others to know that they (the Fitbit wearer) are trying to keep themselves healthy. Because of this, the presenter (influencer) is more selective about the items they present to the group because the influencer wants to assimilate the group and foster group agreement (Jensen Schau \& Gilly, 2003). While a vigorous search of the literature did not disclose a study of specific wellness product consumption, it can be assumed that wellness product consumption would follow the trend of self-idealization that Jensen Schau and Gilly presented.

According to a study done by Mudambi and Schuff (2010), authenticity is the reason social media influencers are more trusted than traditional advertising. In their study, Mudambi and Schuff examined Amazon online reviews via textual analysis and determined that those which were more trustworthy were those posted by a seemingly "ordinary" person. In this sense, authenticity refers to influencers representing themselves as an individual rather than being directly connected to a brand (Mudambi \& Schuff, 2010). Influencers represent a third party, and the origin of the message is not perceived as being from the marketer. Accordingly, influencers 
use techniques like posting selfies, creating original content (unique images with creative captions), and interacting directly with followers to fulfill the role of being authentic third parties, thus, assimilating themselves and their self-presentation to the wishes of a larger audience (Audrezet et al., 2018). Upon existing review of her literature, Barreto (2014) also finds that individuals will adjust their behavior to align with their self-presentational goals to convey a more positive self-image to others. This falls in line with the findings of Segupta et al. (2002) where they conducted three experiments and observed, in all cases, that individuals are willing to exaggerate product claims if it is in their interests of self-promotion.

According to the self-presentation theory, influencers should portray their audience's views through their self-presentation since the audience has control over the success or detriment of the influencer (Baumeister \& Hutton, 1987). The influencer acts as a proxy of the larger audience by portraying that group's values through the products the influencers promote (Jensen Schau \& Gilly, 2003). In Djafarova and Trofimenko’s study on the credibility of microcelebrities on social media (2018), they found that self-presentation theory is of paramount importance when studying influencer endorsement on social media since individuals share extensive amounts of information about themselves. Through in-depth interviews, Djafarova and Trofimenko found that influencers will post pictures that portray themselves more positively in high-quality images, even if it is not a reflection of reality, so that their audience will be satisfied and continue to follow them. Instagram users found those high-quality images inspirational even though they may not be realistic because they liked to see the presented lifestyle of the influencer (Djafarova \& Trofimenko, 2018). Unlike Goffman's initial interpretation of self-presentation theory, it seems that these influencers are going out of their way to give consumers a glimpse into the backstage of their lives (Sweetser \& Keshelashvili, 2005). However, Goffman's self- 
presentation theory still holds strong because these "backstage glimpses" are usually not real interpretations of the influencers' lifestyle.

Although some scholars have studied the effects of self-presentation on the heuristic processing and buying patterns of the audience (Axsom et al., 1987; Casalo et al., 2019; Sokolova \& Kefi, 2020), the perceived credibility of the influencer (Djafarova \& Trofimenko, 2018; Audrezet et al., 2018;), or increased engagement (Tafesse \& Wood, 2020), it appears that none have studied how self-presentation theory affects how influencers present themselves in terms of a common trend like wellness.

\section{Social Media Influencers}

According to Tafesse and Wood (2020), influencers gain their following by crafting authentic online personas, and young adults are more likely to follow influencers who represent their same values (Mintel, 2020a). Miller and Levine (2019) argue that the source delivering the marketing message greatly influences persuasion effectiveness. They say that perceived competence, expertise, and trustworthiness contribute significantly to source credibility. Not only that, but it also seems that individuals may want that source to mirror a better image of themselves. The audience is looking for someone who will mirror their ideal values (Jensen Schau \& Gilly, 2003). According to Barreto (2014), consumers turn to the internet to connect with others and share their "consuming passions" to fulfill the basic human need of sharing information about common interests. This is helpful for extrapolating the audience's values and ideals regarding wellness by studying the content of influencers they follow.

The influencer is motivated by self-presentation theory to match their presentation to their audience's expectations and preferences (Sweetser \& Keshelashvili, 2005). The influencer acts as a facilitator of information and shares this information about products and lifestyles so 
consumers then have a platform to openly discuss. To decide what information is relevant and appropriate to share, influencers create a mental conceptualization of their audience (Ham et al., 2019). This conceptualization can be guided by the information that consumers share on the influencer's content via comments, likes, or shares.

Influencer marketing is growing and global spends are projected to reach $\$ 10$ billion in 2020 (Ham et al., 2019). When influencers make product recommendations through their social media channels, this is known as online word of mouth communication (Barreto, 2014). Barreto asserts that word of mouth has been recognized as one of the most influential sources of information since the beginning of human society. According to a qualitative study done by Tafesse and Wood (2020) in which they examined a specific dataset of Instagram influencers, not only are influencers influential because they utilize the power of word of mouth, but they also create psychological bonds with their followers by sharing personal content about their lifestyles and interests.

Sokolova and Kefi conducted a qualitative study (2020) examining the relationship between parasocial, or one-sided, interaction and credibility of influencers. They found that consumers are more likely to turn to social media for help in making their everyday decisions. Brands have increasingly been turning to influencer marketing to understand potential customers and connect with them through social media (Tafesse \& Wood, 2020). User-generated content on social media is more popular and effective than traditional advertisements due to social media's two-way conversational nature and its ability to capture audience attention, an important factor when acknowledging the effectiveness of advertising (Welbourne \& Grant, 2016). When brands participate in this community, they are sharing knowledge and making consumers active participants in creating brand perceptions (Sokolova \& Kefi, 2020). Influencers and their 
audiences mirror this relationship. According to Casalo et al. (2018), influencers have a serviceoriented mindset meaning that they would willingly portray their audience's ideals.

\section{Instagram Influencers}

According to Casalo et al. (2020), Instagram is the platform most used by influencers due to its sense of immediacy in terms of followers' visual interaction with influencers. Chua and Chang (2016) chose to use Instagram for their study on teenage girls' engagement in selfpresentation on social media because it was the most popular photo-sharing social media site, at the time of the study, and photographs are an important part of self-presentation because they allow individuals to communicate with peers visually. Chua and Chang (2016) state that modern scholarly literature is lacking in the research on this connection between self-presentation and visual social media even though photo-sharing has become increasingly popular.

Instagram fosters the same sense of community that Sokolova and Kefi (2020) mentioned in their study. The engagement rate (the speed at which individuals can interact with a post and each other via comments, likes, and direct messages) was higher on Instagram than any other social media platform (Casalo et al., 2018). This engagement is how influencers' audiences provide feedback on their performance. According to Mintel's Internet Influencer's Report (2020a), although smaller influencers, or micro-influencers, have smaller audience sizes, they achieve higher levels of engagement with their audience. This engagement is a result of higher trust in the influencers. Having a smaller following encourages more interaction since followers believe their voices will be heard (Tafesse \& Wood, 2020; Mintel, 2020a). It should be noted that while these influencers' followings are considered small, they still have relatively large followings, compared to non-influencers, of around 10,000-100,000 followers although this number varies through research and is not standardized (Gomez, 2019). 


\section{Lifestyle Influencers}

According to a survey done by Forbes, $48 \%$ of marketers stated that "lifestyle experts" were the type of influencers in the highest demand (Schwab, 2016). Arguably, lifestyle influencers' content better represents a holistic view of their self-presentation since it centers around one specific influencer and their personal life.

When it comes to social media culture, users are now less willing to follow a myriad of influencers. According to Mintel's Internet Influencers Report (2020a), social media users are following a smaller number of diverse categories, culling their social media to reflect only categories they are deeply passionate about. This creates a deeper relationship with the influencer promoting these select categories (Mintel, 2020a). However, according to Tafesse and Wood (2020), influencers with a wider range of content have higher engagement with their followers. Putting these two together, it can be argued that consumers are following a smaller number of influencers that represent diverse interests.

\section{Young Adult Audience}

According to Goldhill (2018), young adults are important to the advertising world because they are the early adopters. They are the generation that pushes innovation and culture to the foreground. Brands need to demystify their worlds to stay on pace with the changing and fast-paced times. Demystifying the definition of wellness is an important first step in the process of uncovering how young adults interact with their world today.

According to Sokolova and Kefi (2020), Generation Z is more likely to feel "addicted," (p. 6), to influencers and be persuaded by their sponsored posts. This could perhaps be because, according to Mintel (2020c), Gen $\mathrm{Z}$ is following the trend of lessening their diverse followings to only follow influencers who share their values. Having similar values is more important to 
Generation $\mathrm{Z}$ than the attractiveness of the presenter, a finding uncommon to other generations (Sokolova \& Kefi, 2020). Generation $\mathrm{Z}$ is highly reachable via Instagram with $95.8 \%$ using the platform, according to an RPA report (2018).

MOJO Ad's 2019 report on the state of the YAYA (youth and young adults aged 18-24), uncovered that this specific age group approaches wellness differently than any other generation. This age group is most likely to actively seek out healthy alternatives in every area of their lives and is actively doing this every day. Because of this, these young adults turn to others to help them understand and carry out their wellness routines (MOJO Ad, 2019). This data supports Generation $\mathrm{Z}$ as the ideal audience for this research with the selected research method.

\section{Existing Definitions of Wellness}

According to James Miller (2005), the first mention of the term wellness was in 1654 to describe the opposite of illness. He found that, throughout time, the term has evolved, taking great hold in the 1950s and 1970s. Eventually, it has evolved to become a holistic concept of physical, mental, spiritual, and social well-being. Across studies, Generation Z is using wellness and broadly attributing the term to psychological well-being, physical health through dieting, and self-care (Mintel, 2020a; RPA 2018).

The Global Wellness Institute, a non-profit organization, (2018) defines wellness as "the active pursuit of activities, choices, and lifestyles that lead to a state of holistic health" (p. iii). According to the Wellness Economy Monitor report from the Global Wellness Institute (2018), the wellness economy is a $\$ 4.2$ trillion business that spans across ten sectors. However, the Lieberman study (2018) states the self-improvement market is an $\$ 11$ billion industry, highlighting the fact that self-improvement is only a sector of the wellness market. The World Advertising Research Center (2020) states that the increasing consumer interest in health and 
wellness is driving the creation of new product categories touting healthier alternatives such as gluten-free or paleo diets and beauty and household products free from harmful chemicals.

According to Mintel's Global Consumer Trends for 2030 (2020b), the wellness trend is fueled by consumers looking for a holistic approach to long-term physical, mental, and emotional health. The same report also states that growing awareness of environmental concerns opens up another aspect to wellbeing. Now, consumers are actively making purchases to protect their holistic wellbeing as well as the planet's. Ultimately, consumers want a personalized account of what they can do to live their lives "well" (Mintel, 2020b). This need for personalization may spring from the fact that the public is confused about how to act upon their wellness (Cederstrom \& Spicer, 2015). Wellness is a common end goal. Consumers turn to the internet to define what it means to be well, and the term "health and wellness" has been commodified to sell products that tap into the inherent consumer desire to stay healthy and avoid trips to the doctor (Cavusoglu \& Demirbag-Kaplan, 2017).

Wellness is one of the defining trends of the digital generation (Mintel, 2020b). It has redefined the way we work, study, and generally live our lives (Cederstrom \& Spicer, 2015). The term spans across several different disciplines, including economy, health, beauty, fashion, food, drink, home, and technology to name a few (Euromonitor, 2020). Current existing definitions of wellness are scattered. In their book titled The Wellness Syndrome, Carl Cederstrom and Andre Spicer (2015) state that the public is confused about how to carry out their wellness journey. The public is unsure of whether they should pursue moderate happiness in each category of their life or plunge into excess enjoyment. Their book exemplifies this confusion by looking at what colleges around the country offer as "wellness" programs. For example, the University of Massachusetts has its students sign a wellness contract by agreeing to live an alcohol and drug- 
free lifestyle. However, the University of North Dakota's wellness program takes a more holistic approach by offering physical, social, emotional, environmental, spiritual, and intellectual wellness solutions. Syracuse University offers field trips to local parks and lakes, free meditation and yoga, and parfait nights (Cederstrom \& Spicer, 2015).

The inconsistent literature definitions have larger impacts than general confusion on how to embody wellness. According to Alice Baker and Chris Rojek from the University of London (2020), online wellness claims are extremely hard to regulate since they are not directly related to health and, therefore, do not fall under usual health guidelines when suggesting treatments or diets. This makes it imperative that research asks the public themselves to understand this term. If wellness has a clear definition, regulations can be made to stop the inaccurate claims made by potentially harmful wellness products.

\section{Research Questions}

A similar study was done by Lena Cavusoglu and Melike Demirbag-Kaplan in 2017 in their effort to define laypeople's vision of health through Instagram users. They researched Instagram by using a Google add-on to search for 100 instances where the hashtag "\#health" appeared on five separate days. They conducted a textual analysis of the captions and other hashtags that surrounded "\#health," and followed by conducting a content analysis of the collected images alongside their respective captions. Through the combination of their textual and content analyses, they were able to distill laypeople's definition of health into four categories: food, fashion, fitness, and feelings (Cavusoglu \& Demirbag-Kaplan, 2017).

Overall, this study will examine the research question "How do lifestyle Instagram influencers present wellness?” In a similar vein as the Cavusoglu and Demirbag-Kaplan study, this study will seek to define 18-to-24-year-olds' view of wellness as shown by a content 
analysis on the posts of Instagram influencers who appeal to this age range. Additional topics that will be answered through my content analysis are "How do the products Instagram influencers promote exhibit wellness?" and "What are the commonalities between lifestyle Instagram Influencers' wellness content?” These questions ensure that I am studying the holistic presentation of the influencer themselves rather than only capturing portions of their commercially presented selves on sponsored posts. This aligns with self-presentation theory by stating that individuals will alter their entire presented selves to please an audience.

Upon detailed research, there has been no literature found that attempts to define commodified wellness through young adult content. Instead, studies have been focused on what the wellness industry produces (World Advertising Research Center, 2020; Yao, 2020). An article by O’Neill (2020) identifies that influencers on Instagram who self-dub themselves wellness entrepreneurs lead the current wellness trend that has started on social media and grown into a well-being empire.

Many studies have researched the effectiveness of Instagram influencers on young adult decision-making (Casalo et al, 2018; Gomez, 2019; Ham et al., 2019; Miller \& Levine, 2019; Sokolova \& Kefi, 2020), but I will be taking a different approach by studying how influencers present themselves and their ideas to the audience. According to Casalo et al. (2018), followers of the influencer are seen as co-producers of content as the influencer plays into the selfpresentation theory and changes their online presentation to please the feedback coming from their audience. Following this mindset, we would deduce that influencers would portray the wellness trend and provide general guidance in line with what their followers aspire to be because social media allows for two-way communication. 
RQ1: How do self-described wellness influencers on Instagram present wellness to their young adult audiences?

RQ1a: How do the products or paid content in these influencers' posts present wellness to their young adult audiences?

RQ2: What are the commonalities among the content streams of self-described wellness influencers on Instagram?

This literature review has shown the importance of finding answers to these questions. Next, this proposal will examine the methods that will be the framework for the study. 


\section{Chapter 3: Method}

The aim of this study was to explore the meanings of wellness as understood by young adults aged 18-24 by studying the self-presentation of lifestyle social media influencers who selfidentify as wellness experts. This section explores the means by which this study was conducted including the research materials, coding methods, and steps that were taken. Self-presentation theory has guided this research to answer the research questions.

\section{Research Materials}

This study used qualitative methods on textual and visual data generated by microinfluencers (with between 1,000 and 100,000 followers) on Instagram. This falls in line with Mayring's (2004) assertion that content analysis can be applied to various types of content including textual and pictorial. Neuendorf and Kumar (2015) suggest that human analysis of data preserves the strength of a content analysis, and a digital tool is only to be used in conjunction with personal analysis and in situations that contain large amounts of data. The dataset for this study was kept relatively small so it could be performed personally, without a third-party textual analysis tool, in order to preserve the strength of content analysis.

Instagram was chosen as the data source since it is the platform most used by influencers (Casalo et al., 2020). According to Highfield and Leaver (2014), the unique nature of Instagram that combines text and image in every post offers key information when analyzed qualitatively. This method of combining pictorial and textual content analyses uncovers hidden phenomena that could easily be overlooked when studying more text-based platforms such as Facebook or Twitter (Highfield \& Leaver, 2014). 
According to Tran (2020), Instagram has over 1 billion monthly active users. That number was last updated by Instagram in 2018. Of those 1 billion users, $75 \%$ fall into the young adult category aged 18-29. In fact, 67\% of young adults aged 18-29 use Instagram. Globally, there is close to an even gender split with $52 \%$ of the platform being female and $48 \%$ being male users. It is also a very global platform; the United States is the country with the highest number of Instagram users at 116 million users, but $89 \%$ of Instagram users fall outside of the U.S. Research also shows that $60 \%$ of people say they discover new brands on Instagram (Tran, 2020). All of these statistics show that Instagram is a platform ripe for influencers to suggest products and lifestyles to a wide array of young adults.

Since, according to the World Advertising Research Center (2020), health and wellness brands speak to women disproportionately more than men, all of the influencers chosen for this study were women. The influencers targeted specifically say in their Instagram bio that they specialize in "wellness" and their content is a holistic representation of their self-presented lifestyle rather than just focusing on beauty, health, or fashion. Wellness is broadly defined as a holistic view of health that encapsulates physical, spiritual and emotional elements. Since research has found that pleasing-the-audience self-presentation theory can lead to deception on the part of the influencer in their interests of self-promotion (Barreto, 2014; Audrezet et al., 2018), I only studied the self-presentation of the influencers in regards to wellness through their Instagram content and the types of items they promote on their Instagram. I did not study the effectiveness of any products promoted.

This study utilized the Upfluence Influencer Search Tool to find influencers. Upfluence is an influencer database that identifies influencers across all social media platforms using datadriven technology. This influencer marketing platform is currently trusted by Amazon, Asics and 
Verizon to aid in the search for relevant brand influencers. Upfluence has a database of over 4 million influencers that users can search to find the correct influencer for their needs. For the purposes of this study, influencers were searched using the following filters: must use the English language, micro-status of less than 100,000 followers yet with over 1,000 followers, content must include the term "wellness," and a majority of their audience must be aged 18-24. According to Hootsuite, the average engagement rate on Instagram in 2019 was $2.1 \%$ (Sehl, 2019). Since self-presentation theory works best when the audience has a stake in the presenter's success (Baumeister \& Hutton, 1987), I only selected influencers who had a higher-than-average engagement rate, or above $2.1 \%$. The table found in the Appendix shows the 15 influencers the Upfluence Influencer Search Tool provided for use of this study.

\section{Coding}

This study utilized open coding. Since the selected influencers have expressed that their content includes wellness themes by stating in their bio that they have an expertise in wellness, their content served as a guidebook to the definition of wellness. Influencer bios can be found in the Appendix. Photographic and textual content were analyzed separately following the Cavusoglu and Demirbag-Kaplan (2017) study. Influencers' textual content was analyzed once individually through open primary-cycle coding then again during secondary-cycle coding within the context of all influencers studied. According to Tracy (2020), open coding suggests that the material itself drives the research. Primary-cycle coding included the examination of data and then identified words or phrases that capture the essence of the materials and these served as first-level codes. First-level codes were applied once themes were discovered and the textual content was re-analyzed with the codes applied. This study also utilized the constant comparative method pioneered by Glaser and Strauss (1967) as explained by Tracy (2020) to mean that codes 
were subject to modification throughout the entirety of the study as more information becomes clear. Secondary-cycle coding was then utilized as first-level codes were split into more specific and interpretive concepts. Pictorial content was analyzed to provide deeper meaning to the textual analysis. Photographs were then coded alongside their corresponding caption from the textual analysis (Tracy, 2020).

\section{Steps}

This study was structured similar to that of Cavusoglu and Demirbag-Kaplan's (2017); however, this study was looking at influencers rather than laypeople on Instagram. The hashtag search tool was not utilized since the entire influencer's self-presentation was analyzed through their self-curated Instagram feed. Since the selected influencers self-categorized themselves as wellness experts, this paper studied the entirety of their content within a given timeframe and not only the posts that include the word "wellness." The timeframe for this study followed Cavusoglu and Demirbag-Kaplan's structure by identifying five of the most recent posts made by the influencer and another five posts made six months prior. The timeframe was set six months apart to check the results from the first round of posts and eliminate seasonal effects (Cavusoglu \& Demirbag-Kaplan, 2020). The study set was kept small with 10 posts per influencer because of the suggestion from Neuendorf and Kumar (2015). This is to ensure the dataset can be qualitatively analyzed by hand without the help from a textual analysis software. That amounts to studying 15 influencers with ten posts each resulting in 150 posts overall.

\section{Data Analysis}

The content analysis took place in two parts, much like Cavusoglu and DemirbagKaplan's 2017 study. The first section consisted of a textual analysis analyzing the captions of the influencers' photographic content on their account. The text was analyzed to identify similar 
words or phrases used across the influencers. The next section is a content analysis of the photos and videos the influencer has posted. This study has examined commonalities across the influencers' photo and video content including commonalities in theme and topic. It should be noted that video analysis was distributed among both the textual and photographic analysis. If the video included text, that text was included and coded in the same way as other textual content. The rest of the visual video content was coded in the same way as the photographic elements by determining video elements and tone. Those posts with the most similar words and phrases paired with common photo and video content trends represent a shared wellness definition among Instagram influencers.

\section{Textual Analysis}

The primary analysis of captions highlighted similar word choices, themes, hashtags, branded content, tagged accounts, and message tones of each influencer. Each category was then included in an individualized write-up for each influencer including how many times a common word was used, common themes found more than once across that influencer's content, branded content, hashtags that were used more than once, and a generalized conclusion.

All of the influencers' write-ups were then cross-analyzed to determine commonalities among each category. Commonalities were organized from greatest number of appearances to the least and categorized by theme. Themes that stood out as having a greater number of occurrences were translated into first-level codes.

Nouns, verbs, and adjectives that were used more than once in an influencer's content were highlighted. Similar word choices were studied as "exact words used.” Nouns, verbs, and adjectives were chosen due to their ability to hold valuable content. Other word forms such as pronouns or conjunctions were deemed irrelevant and were not counted if they appeared more 
than once. Similar topics the influencers discussed in the captions of their posts were studied as “common themes." Hashtags that were used more than once by an influencer were highlighted and organized into themes. Any branded content was also noted in the research. To determine if content was branded, the item had to be tagged in the caption. Tagged accounts were noted in the research if they appeared more than once across a single influencer's content, and the overall textual tone of each post was noted in the research.

\section{Photographic Analysis}

The primary analysis of photographic content was conducted on the entire post as one entity, even if that post included multiple pictures. This was done to determine the tone, content, dominant colors, and purpose of the entire post. Instagram also applies the same filter to every photo in a post, so all photo tones of a single post remained the same. Initial codes were

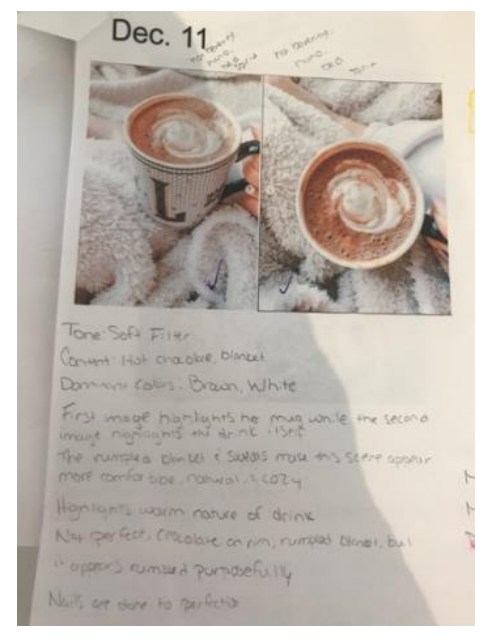
determined by cross-analyzing all of the initially researched elements. It was found that only neutral colors such as white or beige were common across all influencers, so dominant photo colors were deemed irrelevant.

Photo tone was studied in the research as the overall feel of the post. Some posts were merely modified instead of being outrightly filtered and that was noted. General photographic topics and content were then personally scanned for commonalities. After initial codes were determined, first-level codes were applied to every photo amounting in 247 coded photos. This was done because the content was different from photo to photo and codes needed to be applied directly to photo content.

\section{Method Choice}


According to Brennen (2017), texts are seen as cultural artifacts that help individuals make sense of their everyday lives. These texts can be anything that is used to make meanings including physical texts or pictures. Specifically, a rhetorical analysis is used in situations when researchers are studying instances of influence or persuasion. This specific type of textual analysis considers the relationship between a text, its author, and its audience (Brennen, 2017). This kind of analysis will provide rich information when examining the author and audience against the self-presentation theory.

The pictorial portion of the content analysis was used much like it was used in Cavusoglu and Demirbag-Kaplan's (2017) study. In their study, they used pictorial content analysis to confirm and further explore the findings from the textual analysis. They also cite that qualitative research exploring photographs has already been found to represent personal experiences directly. There is a direct relationship between images and the content of the message (Cavusoglu \& Demirbag-Kaplan, 2017). Chua and Chang (2016) find that the younger generation uses photos for live communication rather than for keepsakes or memories, and photographs are one of the best forms of self-presentation since they are an integral part of young adult conversation. 


\section{Chapter 4: Results}

After the analysis was complete, data was assembled in various charts. This section will review the results from these analyses.

\section{Word Usage}

The chart below indicates usage of various words encountered during the analysis (see Figure 1.1) The first number indicates how many times the word was used overall and the second number after the dash indicates how many influencers used this exact word. Words were then grouped into themes. Themes were determined by word content or the context they were used in. For example, all of the words under the happiness column were used to express moments of happiness for the influencer, and words in the external column were used when the influencer referenced an external event that had affected them.

Words were only counted in their exact form with the exception of two words. The first exception included the heart emoji. This was the only emoji counted in the study because of the amount of times it had appeared in research. Upon further inspection of the table, it appeared that only one influencer utilized the heart emoji more than once in their content. The other exception included the word "self." The word "self" was counted for the words "self," "myself," "yourself," or "herself." These were grouped together because they were found in the research to have the same meaning. All of these words put a focus on the individual self and their own wellness journey. More research was done under the "relation to others" table by breaking these instances up by relational wording.

\section{Figure 1.1}

\begin{tabular}{|l|l|l|l|l|l|l|l|}
\hline Exact Words \\
Used
\end{tabular}




\begin{tabular}{|c|c|c|c|c|c|c|c|}
\hline Happiness & Food & Body & Individual & Exercise & External & $\begin{array}{l}\text { Other } \\
\text { Adj. }\end{array}$ & Mental \\
\hline Happy (28-7) & $\begin{array}{l}\text { Smoothie } \\
(14-3)\end{array}$ & Health (27-6) & $\begin{array}{l}\text { Self } * \text { including } \\
\text { myself, } \\
\text { yourself, and } \\
\text { herself* (17-5) }\end{array}$ & $\begin{array}{l}\text { Workout (23- } \\
\text { 3) }\end{array}$ & $\begin{array}{l}\text { Holidays } \\
(10-3)\end{array}$ & Good (7-3) & $\begin{array}{l}\text { Journal (7- } \\
\text { 3) }\end{array}$ \\
\hline Love (21-5) & $\begin{array}{l}\text { Vegetable } \\
(10-2)\end{array}$ & $\begin{array}{l}\text { Kinesiologist } \\
(6-1)\end{array}$ & Mind (2-1) & $\begin{array}{l}\text { Weights (4- } \\
\text { 1) }\end{array}$ & Change (4-1) & Easy (7-2) & Mental (7-3) \\
\hline Friend (9-4) & $\begin{array}{l}\text { Cookie (8- } \\
2)\end{array}$ & Digestion (4-1) & Mood (2-1) & $\begin{array}{l}\text { Movement } \\
(3-1)\end{array}$ & Year $(3-1)$ & $\begin{array}{l}\text { Simple (6- } \\
\text { 1) }\end{array}$ & $\begin{array}{l}\text { Meditation } \\
(5-1)\end{array}$ \\
\hline Favorite (13-2) & Green (6-2) & $\begin{array}{l}\text { Blood Sugar (3- } \\
\text { 1) }\end{array}$ & Personal (2-1) & $\begin{array}{l}\text { Kettleball (2- } \\
1)\end{array}$ & $\begin{array}{l}\text { Birthday (3- } \\
\text { 1) }\end{array}$ & Little (4-1) & $\begin{array}{l}\text { Mindful (4- } \\
\text { 1) }\end{array}$ \\
\hline Enjoy (4-2) & Cook (6-2) & $\begin{array}{l}\text { Parasympathetic } \\
(3-1)\end{array}$ & & & $\begin{array}{l}\text { Quarantine } \\
(2-1)\end{array}$ & Small (4-1) & Yoga (3-1) \\
\hline Heart (emoji) (5-1) & $\begin{array}{l}\text { Recipe (5- } \\
\text { 2) }\end{array}$ & $\begin{array}{l}\text { Nervous System } \\
(2-1)\end{array}$ & & & Week (2-1) & $\begin{array}{l}\text { Perfect (2- } \\
1)\end{array}$ & Routine (3-1 \\
\hline Homies (3-1) & Eat (6-1) & Wellness (2-1) & & & $\begin{array}{l}\text { Weekend (2- } \\
1)\end{array}$ & $\begin{array}{l}\text { Beautiful } \\
(2-1)\end{array}$ & Travel (3-1) \\
\hline Joy (2-1) & $\begin{array}{l}\text { Protein }(5- \\
1)\end{array}$ & & & & $\begin{array}{l}\text { Summer (2- } \\
1)\end{array}$ & Filling (3-1) & Reflect (2-1) \\
\hline Smile (2-1) & Prep (5-1) & & & & & $\begin{array}{l}\text { Important } \\
(2-1)\end{array}$ & \\
\hline Rainbow (2-1) & Wash (4-1) & & & & & $\begin{array}{l}\text { Physical (2- } \\
\text { 1) }\end{array}$ & \\
\hline Fun $(2-1)$ & Salad (4-1) & & & & & $\begin{array}{l}\text { Creative (2- } \\
1)\end{array}$ & \\
\hline Sun (2-1) & Meal (4-1) & & & & & Weird (2-1) & \\
\hline \multirow[t]{20}{*}{ Want (2-1) } & Coffee (4-1) & & & & & $\begin{array}{l}\text { Present (2- } \\
1)\end{array}$ & \\
\hline & Herb (3-1) & & & & & & \\
\hline & $\begin{array}{l}\text { Collagen } \\
(3-1)\end{array}$ & & & & & & \\
\hline & Vegan (3-1) & & & & & & \\
\hline & $\begin{array}{l}\text { Pancake (3- } \\
1)\end{array}$ & & & & & & \\
\hline & $\begin{array}{l}\text { Organic (3- } \\
1)\end{array}$ & & & & & & \\
\hline & $\begin{array}{l}\text { Muffin (2- } \\
1)\end{array}$ & & & & & & \\
\hline & Cups (2-1) & & & & & & \\
\hline & Carb (2-1) & & & & & & \\
\hline & $\begin{array}{l}\text { Gingerbread } \\
(2-1)\end{array}$ & & & & & & \\
\hline & $\begin{array}{l}\text { Coconut (2- } \\
1)\end{array}$ & & & & & & \\
\hline & Wine (2-1) & & & & & & \\
\hline & $\begin{array}{l}\text { Parsley (2- } \\
1)\end{array}$ & & & & & & \\
\hline & $\begin{array}{l}\text { Powder (2- } \\
1)\end{array}$ & & & & & & \\
\hline & Snack (2-1) & & & & & & \\
\hline & Water (2-1) & & & & & & \\
\hline & Food (2-1) & & & & & & \\
\hline & Fats $(2-1)$ & & & & & & \\
\hline & $\begin{array}{l}\text { Sipping (2- } \\
\text { 1) }\end{array}$ & & & & & & \\
\hline & Fruit $(2-1)$ & & & & & & \\
\hline
\end{tabular}

Happiness and food-related wording was most common while happiness wording was more condensed than food wording meaning that fewer words were used to describe happiness, but those words were commonly found across most of the influencers' content. Interestingly, 
food terms were often foods that were sweet or comforting. Terms having to do with the body were mainly related to physical health and were also used frequently, but they were used most frequently by a niche influencer who focused specifically on her lifestyle which prioritized bodily health. Other influencers did mention the word "health" but it was often used in a holistic context speaking about physical and mental health together. Words that expressed individuality were not very common, but the theme of "self" was apparent in the research. Many influencers used this word frequently to describe the personalization of their wellness journey. This recalls previous research from the literature review that states how, ultimately, consumers want a personalized account of what they can do to live their lives "well” (Mintel, 2020b).

\section{Common Themes}

The second chart dealt with themes (see Figure 1.2 below). The most common themes among this category were: happiness, food, body, individual, exercise, external, other adjectives, and mental health. This follows along with themes found in the literature review that wellness encompasses holistic health including physcial health, dieting, and mental health (Mintel, 2020b). These themes are organized from left to right reading most mentioned to least mentioned. The other themes appeared in less than three of the studied 15 influencers and were deemed irrelevant.

\section{Figure 1.2}

\begin{tabular}{|l|l|l|l|}
\hline Common Themes & Relation to Others & Mental & Happiness \\
\hline Eating & $\begin{array}{l}\text { She talks to her followers as } \\
\text { if they are her friends (4) } \\
\text { wellness (8) }\end{array}$ & Be grateful (6) & $\begin{array}{l}\text { Focus on what makes you } \\
\text { happy and positive (5) }\end{array}$ \\
\hline $\begin{array}{l}\text { Healthy eating can be easy } \\
\text { (3) }\end{array}$ & $\begin{array}{l}\text { Wellness is an individual } \\
\text { journey (4) }\end{array}$ & $\begin{array}{l}\text { Sometimes everyday things } \\
\text { go unnoticed }\end{array}$ & $\begin{array}{l}\text { Doing things that make you } \\
\text { happy is important }\end{array}$ \\
\hline $\begin{array}{l}\text { Picking the right foods is } \\
\text { important }\end{array}$ & $\begin{array}{l}\text { Taking care of yourself is } \\
\text { important }\end{array}$ & $\begin{array}{l}\text { We have too many } \\
\text { distractions, just stop and } \\
\text { think }\end{array}$ & Find what you love \\
\hline $\begin{array}{l}\text { Eating healthy doesn't have } \\
\text { to mean starving yourself }\end{array}$ & $\begin{array}{l}\text { She let others' thoughts and } \\
\text { opinions matter, but now } \\
\text { she's putting her own } \\
\text { opinions first }\end{array}$ & $\begin{array}{l}\text { Being mindful is a key to } \\
\text { wellness }\end{array}$ & $\begin{array}{l}\text { She makes time for and } \\
\text { looks forward to things that } \\
\text { make her happy like fashion, } \\
\text { music, and friends }\end{array}$ \\
\hline
\end{tabular}




\begin{tabular}{|l|l|l|l|}
\hline $\begin{array}{l}\text { Simple food alterations can } \\
\text { taste good and be healthier }\end{array}$ & $\begin{array}{l}\text { She is on our side (us vs. } \\
\text { them) }\end{array}$ & $\begin{array}{l}\text { Mental activities are a part of } \\
\text { wellness }\end{array}$ & Fashion makes her happy \\
\hline & $\begin{array}{l}\text { Making others feel loved and } \\
\text { appreciated is important }\end{array}$ & $\begin{array}{l}\text { Self-reflection can put big } \\
\text { themes into perspective }\end{array}$ & $\begin{array}{l}\text { Seeks positivity in negative } \\
\text { situations }\end{array}$ \\
\hline & $\begin{array}{l}\text { Being relatable to her } \\
\text { followers }\end{array}$ & $\begin{array}{l}\text { Listen to what your body } \\
\text { wants }\end{array}$ & $\begin{array}{l}\text { Happiness is a part of } \\
\text { wellness }\end{array}$ \\
\hline & $\begin{array}{l}\text { Your experiences can } \\
\text { strengthen others }\end{array}$ & $\begin{array}{l}\text { We have control over our } \\
\text { own happiness }\end{array}$ \\
\hline & Family is important & & \\
\hline
\end{tabular}

The number in parentheses indicates how many influencers, out of the possible 15 , utilized this theme. These themes represent notions that were present across an influencer's entire content, not just a single post. Themes were grouped together depending on topic. Topics were chosen based on that specific theme's content. For example, if the theme mentioned food or eating in any way it was grouped under a food topic while any theme mentioning others directly was grouped in the relation to others topic. The study utilized the overall topic as a first-round code because some similar themes were noticed among influencers, but were coded slightly different such as "she makes time for things that make her happy like fashion" and "fashion makes her happy." Similar themes that emerged included eating, relation to others, mental health, and happiness. The topic on eating mainly focused around destroying stigmas around healthy food like it has to be bland or hard to make. The relation to others topic highlighted individuality as a strong theme, also following the other topics saying that followers should eat and do what feels good to them. Self-reflection and mental health was another major theme among influencers as many shared personal stories about how they overcame specific moments in their life when they felt their mental health was not ideal. Other topics were not as prevalent among a wide group of influencers and were deemed irrelevant.

\section{Hashtags}

Another point of analysis was hashtags. In the chart below (see Figure 1.3), you'll notice that eight out of the 15 influencers either did not utilize any hashtags or did not utilize any hashtag more than once across their content. This finding was surprising given that the 
Cavusoglu and Demirbag-Kaplan (2017) study focused only on wellness hashtags. Hashtags

were determined to be a supplement to the research found in other categories, but did not provide

much new information to the study. However, specific diets did emerge in the hashtag research

such as anti-inflammatory, low carb, high fiber, vegan and gluten-free lifestyles. These diets

were not mentioned anywhere else in the research and were deemed irrelevant moving forward.

\section{Figure 1.3}

\begin{tabular}{|c|c|c|}
\hline Hashtags & & \\
\hline Food & Health & Working Out \\
\hline \#eatwithlove (5) & \#healthylifestyle (10-2) & \#fitnesstransformation (3) \\
\hline \#eatrealfood (5) & \#wellnessblogger (4-2) & \#fitgirl (2) \\
\hline \#antiinflammatorydiet (4) & \#health (6-2) & \#training (3) \\
\hline \#eatwholefood (4) & \#healthyliving (7) & \#gymshark (2) \\
\hline \#healthyrecipes (4) & \#livingbalanced (7) & \#gymsharkwomen (2) \\
\hline \#healthyfoodie (4) & \#wellness (5) & \#fitness (2) \\
\hline \#food (3) & \#iinhealthcoach (4) & \#letsgetit (2) \\
\hline \#lowcarb (3) & \#investinyourhealth (4) & \#gainsville (2) \\
\hline \#highfiber (3) & \#healthcoach (4) & \#trainer (2) \\
\hline \#lowcarbrecipe (3) & \#mentalhealth (4) & \#otfcoach (2) \\
\hline \#highfiberrecipe (3) & \#collegehealth (3) & \\
\hline \#recipes (3) & \#kinesiology (3) & \\
\hline \#foodblogger (3) & \#mindbodygram (3) & \\
\hline \#goodmoodfood (3) & \#wellnessjourney (3) & \\
\hline \#lowcarbliving (3) & \#wellnessblog (2) & \\
\hline \#nourishyourself (3) & \#mindbodysoul (2) & \\
\hline \#wellandgoodeats (3) & \#healthyhappylife (2) & \\
\hline \#cleaneats (3) & \#wellnessjourney (2) & \\
\hline \#groceryhaul (3) & \#wellthy (2) & \\
\hline \#healthygroceries (3) & \#wellnesslifestyle (2) & \\
\hline \multicolumn{3}{|l|}{ \#shoppingforone (3) } \\
\hline \multicolumn{3}{|l|}{ \#ffactor (3) } \\
\hline \multicolumn{3}{|l|}{ \#ffactorapproved (3) } \\
\hline \multicolumn{3}{|l|}{ \#greensmoothies (2) } \\
\hline \multicolumn{3}{|l|}{ \#healthysmoothies (2) } \\
\hline \multicolumn{3}{|l|}{ \#vegan (2) } \\
\hline \multicolumn{3}{|l|}{ \#glutenfree (2) } \\
\hline \multicolumn{3}{|l|}{ \#keto (2) } \\
\hline \multicolumn{3}{|l|}{ \#paleo (2) } \\
\hline \multicolumn{3}{|l|}{ \#greenlifestyle (2) } \\
\hline \multicolumn{3}{|l|}{ \#healthyeats (2) } \\
\hline \multicolumn{3}{|l|}{ \#eatwellbewell (2) } \\
\hline \multicolumn{3}{|l|}{ \#organicfood (2) } \\
\hline \multicolumn{3}{|l|}{ \#freshfood (2) } \\
\hline \multicolumn{3}{|l|}{ \#plantbasedgoodness (2) } \\
\hline \multicolumn{3}{|l|}{ \#healthyfoodie (2) } \\
\hline \#rd2be (2) & & \\
\hline
\end{tabular}

The first number indicates how many times the hashtag was used overall and the second

number after the dash indicates how many influencers used this exact hashtag. If there is no dash, 
that indicates the hashtag was only used by one influencer. Hashtags were then grouped into themes. The most common themes among this category were: food, health and working out. Food hashtags were mostly different between each influencer indicating that there was not one specific type of food, food group, or diet that correlated specifically with wellness. Noticably, the only hashtags used by more than one influencer were \#healthylifestyle, \#wellnessblogger, and \#health indicating that having a healthy lifestyle is important to wellness; however, these were again only used by two influencers, highlighting the stark difference in content across influencers as well as the small use of hashtags. There were only three influencers who posted about a lifestyle involving exercising or working out, but these influencers spoke about this very frequently, thus earning working out a spot as a theme in this section. This ties in with the previous literature review finding that wellness and health are intertwined by wellness being a preventative measure of health that prevents trips to the doctor (Cavusoglu \& Demirbag-Kaplan, 2017). The other themes were used considerably less and were considered irrelevant.

\section{Branded Content}

The next analysis dealt with branded content. In the chart below (see Figure 1.4), the number indicates how many influencers promoted that same product. To answer the research question "How do the products or paid content in these influencers' posts present wellness to their young adult audiences," posts including promotion were coded and organized according to theme. It was determined that the number of times each influencer promoted a product was not as relevant as how many influencers promoted that product or something similar since most products were only promoted once by each influencer with the exception of protein and collagen supplements. Each product was researched through its tagged Instagram page and given a short 
description. Every product was then categorized into similar themes based on the nature of the product.

\section{Figure 1.4}

\begin{tabular}{|c|c|c|}
\hline Branded Content & & \\
\hline Food & Clothing & Supplements \\
\hline $\begin{array}{l}\text { lilys_sweets - sugar-free sweets } \\
\text { company }\end{array}$ & marmishoeusa- botique footwear & vital proteins - collagen (3) \\
\hline so_delicious - dairy-free products & liketoknow.it - influencer fasion & $\begin{array}{l}\text { nuzest- plant based nutrition and clean, } \\
\text { low carb protein (2) }\end{array}$ \\
\hline $\begin{array}{l}\text { blenderbombs - nutrient-dense } \\
\text { superfod ball }\end{array}$ & $\begin{array}{l}\text { peacecollective - clothing brand that } \\
\text { gives back }\end{array}$ & paradiseherbs - organic supplements \\
\hline lovvelavva- plant-based superfoods & lunya- modern women's sleepwear & ladybugpotions- natural supplements \\
\hline coconutbliss - plant-based ice cream & $\begin{array}{l}\text { inclusivehealthcolllection- clothing that } \\
\text { promotes holistic health }\end{array}$ & \\
\hline breadsrsly- gluten-free sourdough bread & lululemon - athletic/yoga clothing & \\
\hline paleothinfood - USDA organic food & nvgtn- athletic/yoga clothing & \\
\hline $\begin{array}{l}\text { foodforlifebaking - high-quality and } \\
\text { organic sprouted grain breads }\end{array}$ & goldnblooms- gold filled jewelry & \\
\hline $\begin{array}{l}\text { sietefoods - gluten free mexican } \\
\text { american food company }\end{array}$ & $\begin{array}{l}\text { the mayfair group self love collection- } \\
\text { all inclusive body positive clothing }\end{array}$ & \\
\hline $\begin{array}{l}\text { applegate - no antibiotics, growth } \\
\text { hormones, gluten-free food }\end{array}$ & & \\
\hline $\begin{array}{l}\text { lafourmibionique- healthy and hearty } \\
\text { granola blends }\end{array}$ & & \\
\hline $\begin{array}{l}\text { lifewaykefir- probiotic milk with } \\
\text { immunity support and mood boosting }\end{array}$ & & \\
\hline jooliesdates- date company in CA & & \\
\hline $\begin{array}{l}\text { splendidspoon- ready-to-eat, nutrient- } \\
\text { dense, plant-based meal delivery }\end{array}$ & & \\
\hline go_raw- natural sprouted seed snacks & & \\
\hline royal ghee- natural whipped spread & & \\
\hline $\begin{array}{l}\text { livebeaming- organic cold-pressed juice } \\
\text { and superfood smoothies }\end{array}$ & & \\
\hline
\end{tabular}

The most common branded content included food, clothing, and supplements. Other

influencers were also commonly promoted, but the majority of the influencers were tagged to

promote their food brands, and were thus counted in the food category. Supplements was given its own category, but could also be seen as an addition to the food category since a majority of these supplements were protein or collagen. Both of these are commonly added into recipes rather than taken as separate supplements in order to increase the positive effects of food on the body. Other product categories were not mentioned as often and were deemed irrelevant. Since the self-improvement market has grown into an $\$ 11$ billion business, this section provides useful insight into what kinds of products get categorized into that market (Lieberman, 2018). 


\section{Accounts Tagged}

Next, an analysis was done on the accounts tagged (see Figure 1.5). The first number indicates how many times that account was tagged. The second number after the dash indicates how many influencers tagged that account. 10 out of the 15 influencers tagged an account more than once in their content. Because of the large number of accounts tagged, only accounts that were tagged more than once by two or more influencers were determined relevant. These accounts were then grouped into theme with the largest group being other lifestyle influencers followed by food accounts, magazines, and brands.

\section{Figure 1.5}

\begin{tabular}{|l|l|l|l|}
\hline Tagged & & & \\
\hline Influencer & Food & Magazine & Brand \\
\hline her.healthful (18-3) & wellandgoodeats (10-3) & selfmagazine (6-2) & iamwellandgood (13-3) \\
\hline lanibfit (12-2) & thechalkboardeats (7-2) & healthmagazine (5-2) & mindbodygreen (11-2) \\
\hline whattthehealth (12-2) & thefeedfeed (6-2) & womenshealthmag (4-2) & \\
\hline theplanteatingpig (11-2) & healthy_ish (5-2) & & \\
\hline wellnesswithsoph (11-2) & & & \\
\hline shesplantbased (11-2) & & & \\
\hline wellnesswithjojo(8-2) & & & \\
\hline madsmaley (8-2) & & & \\
\hline lifestylewithcath (7-2) & & & \\
\hline bellas_life (5-2) & & & \\
\hline
\end{tabular}

There were only three accounts mentioned by more than two influencers and those included her.healthful (which was herhealthfulplate at the time of the study), wellandgoodeats, and iamwellandgood. Her.healthful was the most mentioned account with 18 mentions across three accounts. She is another wellness lifestyle influencer with $11.8 \mathrm{k}$ followers and her own wellness website. Her bio indicates that she specializes in body and mind connection, and she is a psych student in Toronto. Iamwellandgood is the second most mentioned account with 13 mentions across three accounts. This is a brand with over 1 million followers on Instagram that claims, in their bio, to be decoding and demystifying what it means to live well. This wording was noted in the research as especially interesting since wellness was found in the literature 
review to be inherently confusing and in need of demystifying (Cederstrom \& Spicer, 2015).

Wellandgoodeats was the last account mentioned by three influencers and it was tagged ten times. This page is an offshoot of the Well + Good brand (Instagram page: iamwellandgood) with 194k followers. The page offers food recipes, and its bio claims to specialize in superfoods, nutritious recipes, and healthy hacks. The similarity of these accounts solidifies the research that young adults are culling their social media to reflect a certain set of values (Mintel, 2020a).

Within this found 'wellness community,' values seem to represent the mindset that there are holistic solutions to confusing aspects of wellness since the most popular tagged content revolves around themes found in other sections of this research including food, physical, and mental health.

\section{Textual Tone}

For the textual tone chart (Figure 1.6), the number indicates how many times that tone was used by an influencer out of the 150 posts. If there is no number, that indicates that tone was only used once. It was possible for a post to have more than one tone. For example, a post could have been both informational and witty. The tones were categorized and grouped by theme.

\section{Figure 1.6}

\begin{tabular}{|l|l|l|l|}
\hline Textual Tone & & & \\
\hline Guiding & Joyful & Animated & Friendly \\
\hline Informational (58) & Excited (18) & Inspirational (21) & Conversational (7) \\
\hline Matter-of-fact (8) & Grateful (12) & Wishful (3) & Loving (3) \\
\hline Directional & Happy (9) & Uplifting & Reminiscant (3) \\
\hline Storytelling & Light-hearted (6) & Determined & Encouraging (2) \\
\hline & Proud (6) & & Urging (2) \\
\hline & Witty (5) & & Reassuring \\
\hline & & & Inquizitive \\
\hline & & & Soothing \\
\hline & & & Caring \\
\hline
\end{tabular}

The most common themes that appeared through text were guiding, joyful, animated, and

friendly tones. These tones highlight the one-sided parasocial relationship influencers can have 
with their audiences. These relationships typically serve to portray the influencer as a guide who appears as a friend to their audiences (Sokolova \& Kefi, 2020).

\section{Textual Coding Summary}

After examination of all of the similar textual elements, first-level codes were created. These first-level codes included food, health, happiness, and relation to others. These codes were created from similarities in textual content including the common use of food/eating language and other thematic elements in the text.

Health was chosen because of the prevalence of both mental health and physical health language in primary research. Physical health language was evident in the use of exercise-related hashtags and wording as well as the use of branded supplements. The word "health" itself was also used strongly in the content. Mental health was also evident in wording and hashtag choice as well as a common theme for many posts. These topics were coded under "health" with two sub-codes differentiating the use of physical health and mental health language.

Happiness was a prevalent word choice, thematic element, and tonal choice by many influencers. Happiness served as its own first-level code while also determining the separation between happiness and mental health elements.

Relation to others is determined as another first-level code. The role of this code is to determine how influencers self-present themselves to their audience. Individuality was a common topic in both the word and theme choice of the influencers. This code will determine how the influencer relates to their audience through language choice to understand if the influencers are suggesting they join their influencers' individual journey or if they are merely supporting it from afar. 
First level codes were applied to the original text with food elements outlined in green, health elements outlined in purple, happiness elements outlined in yellow, and 'relation to others' elements outlined in teal.

'Relation to others' elements were initially coded as any element that spoke directly to the audience. It was later determined that this code needed to be broader since the entire caption was a part of the influencer's self-presentation to the audience. This code was redefined and later analyzed by inputting all text into a spreadsheet and separating each text by purpose and point of view including demands, questions, first person singular, first person plural, second person, third person, and other. The purpose of differentiating between first person singular and first person plural wording allows a study of the influencers' personal motives and relational motives. This helps to determine what topics the influencer chooses to relate to and which topics the influencer separates themself from. This code was especially useful in determining how the influencer selfpresented themselves in relation to other codes such as mental and physical health, dieting, and happiness.

Textual point-of-views were often hard to differentiate since most influencers flowed between first, second and third person seamlessly. For example:

"I realized recently that a lot of things are like riding a bike or swimming. you learn it and then you won't do it for a while but then you find yourself pushed in the pool or on a bike and you're totally fine. like muscle memory.

i think we have that a lot for healing and relationships and a lot of life in general. we won't date for months and think we've lost all ability to have a relationship. we fall off and stop treating ourselves well and think we can't get right back to it. we get in a headspace that we can't feel better again, that we forgot what happiness/success feels like etc.

but we can! all the info is still right there. it's about just fucking doing it. and weirdly, a lot of it is instinctual. even the learning part. 
anyways, happy tuesday 毁”

However, influencers most often used first and second person viewpoints differentiating between first person singular and first person plural. First person plural wording used words like we, us, ours, etc... to help the influencer show they relate to topics that are especially hard. These were typically negative things or habits that needed to be changed like changing mindsets toward social media or being in quarantine. Although these topics were more challenging than anything discussed using first person singular or second-person point-of-views, they were always changeable. This viewpoint was most often used in an active state of change and the influencer was using this language to try and get their audience to accomplish something. This led to the specific use of this viewpoint as being inspirational or motivational. Most influencers wanted their audience to know they were not alone and that they were all going to go through and get through this obstacle together. When pointing out the faults in the general "we," influencers used a gentle, guiding tone to encourage the audience that they were going to help them through this. While the third person point-of-view was not used often, when it was used it made a big impact. This viewpoint is used for the sole purpose of highlighting the influencer as a guide. It is used to denote that others are wrong and to encourage an 'us vs. them' mentality. The wording used for wrongdoings in third person are more severe than the wrongs admitted to within the first person plural viewpoint. These missteps are also portrayed as beyond help or guidance and followers are encouraged to let those people go. This is in stark contrast to the first person plural wording used to admit bad habits that can be changed. These unforgivable traits used in third person wording are often about topics the influencer would not want to relate with or admit to such as racism or sexism, and those 'others' are often deemed as a hindrance to an individual's overall wellness journey. For example: 
"Those extra 5 pounds represent tons of popcorn during movie night marathons with your best friends, that extra glass of wine with dinner, eating that amazing blueberry cheesecake from your favourite restaurant.

Don't forego your mental, social, or spiritual health to look a certain way.

Society wants woman to be small. Small in size and in voice. Businesses make money by making us believe we are worthless and their products will make us worthy. You don't need any fancy powders or smoothies to be healthy.

Health comes from within. It comes from mindfulness and consciousness. "Health" shouldn't be hard and it should not be expensive.

Don't let them win."

It should be noted that not all influencers studied used the third person viewpoint in this way, and a few chose to use it as an education tool to inform their audience on the purposes of others.

\section{Photo Content}

Photo content was initially studied by post since each post has a relevant group of photos (see Figure 1.7). First-level codes were then applied to each photo individually resulting in 247 photos.

\section{Figure 1.7}

\begin{tabular}{|l|l|l|}
\hline Photo Tone & & \\
\hline Pure & Enhanced & Filtered \\
\hline Natural (66) & High-Contrast (38) & Soft Filter (33) \\
\hline Sunlight (62) & Bright (31) & Vintage Filter (2) \\
\hline Night & Colorful (5) & Black \& White \\
\hline Warm & High-Sharpness (4) & \\
\hline
\end{tabular}

The number indicates how many posts out of the possible 150 used that photo tone. It was possible for a post to include more than one photo tone. For example, a post could be both bright and colorful. Those tones were then grouped into categories by theme. The most popular photo tones included natural, sunlight, high-contrast, bright, or a soft filter. There was little use of obvious filtering in the research. Most posts aimed to appear more natural with only small photographic enhancements like increasing photo brightness or contrast. Direct sunlight was 
often used to make a photo appear brighter in a more natural way. These small enhancements were often used to hide imperfections especially when used in food images since bright colors made food appeal more fresh and appetizing.

Photos were noticeably as perfect as they could get through the use of photo enhancements while still seeming natural and relatable. This is evidence of the influencers participating in self-presentation theory by allowing their audience to only see what the influencers allow them to see (Goffman, 1959). Influencers would often pose sans makeup with natural hairstyles or purposefully include elements that were imperfect such as a wrinkled blanket or towel in the background. Backgrounds were typically kept simple, most likely to keep the focus on the purpose of the post. Natural elements often made a photo appear less sterile and more visually interesting with bright colors. General themes began to emerge such as: the use of personal elements like a hand or person, natural elements that would appear in nature, any sort of food or drink, and sponsored products. These first-level photo codes were then applied to each of the 247 photos in the study set. Doing this revealed what elements prevailed in each code.

Each photo was studied separately to determine how many times each code appeared. There were 247 photos overall in the study set. You can find the breakdown of photo content in the Appendix.

Each element that was included in over 10 photos was highlighted yellow while each code was highlighted green. The most common photographic elements included a form of personal element meaning that a part of a human was visible in the photo. Natural elements were also prevalent in the photos. Most influencers included some sort of nature element even if it was not the purpose of the photo. Being outside, having plants in the background, or utilizing sunlight to create unique photos were popular ways these influencers incorporated the outside world. 
Food was consistently the most popular topic in the textual analysis, but was pictured in less than half of the photos. Not all influencers posted about or mentioned food, however, every influencer did include some element of themselves or nature. Sponsored products were typically seen in use and out of their packaging. Clothing was a commonly sponsored product, and clothing was only counted as a photographic element if the influencer mentioned this clothing specifically in the caption or by tagging the brand since every instance of a person included them wearing clothing. Workouts were also more popular in the textual analysis than the photo analysis, namely the hashtag research. This was most likely due to the few influencers who posted about working out and their strong use of hashtags compared to other influencers.

When promoting items, the influencers in this study almost always showed that product in use. This shows that the influencer uses and stands behind the item, and most do not show the product at all. For example, if an influencer was promoting a protein powder, they may post an image of a smoothie where the protein powder itself is being used but is not directly visible. Not showing the product label gives the post a more organic feel to portray the idea that the influencer uses this product in their everyday life. Instead of using a corporate tone and image to promote products, these influencers wish for their promotions to blend seamlessly with the rest of their content. To accomplish this, they used the same tonality in photo and text they would use in any other post.

Paid promotion is hard to determine in Instagram posts since most Instagram influencers do not correctly mark advertisements on their content (Forrester, 2020). For the purposes of this research, items that were considered promoted were items that were tagged in the caption. There were 57 promoted items out of 150 posts. Food, clothing and supplements were the most common promotional items featured in these influencers' posts which follow along with the 
research presented in the studied text. Food items were promoted 17 times while clothing items were promoted nine times and supplements were promoted seven times. Food items were usually "healthier" alternatives to everyday food items such as sugar-free sweets or dairy-free products. Most of the promoted food was touted as natural or organic and was shown as a better substitute for traditional baking items. The food items that the influencers' promoted were always used in another recipe and were never featured on their own in a post. Clothing items that were being promoted were most often athletic wear or 'clothing with a cause' meaning that the clothing brand supported a larger cause or organization such as inclusivity or Black Lives Matter. Promotions in the supplement category focused on bettering the self from the inside out with supplements such as collagen, protein, and various natural or organic varieties. Skincare was also a popular promotion with many influencers posing with various masks, cleansers, or zit treatments.

\section{Results conclusion}

The results of this research concluded in three general topics that answer how wellness influencers' self-presentation helps young adults understand wellness: personal relationshiops, guiding mentality, and happiness. Personal relationships indicate how personal the wellness journey can be, and it is natural that Instagram users would want to turn to an influencer with a guiding mentality to guide them through. The guiding mentality topic also indicates that the wellness journey itself is confusing and that a person could benefit from having a guide. The wellness journey overall leads to happiness as these wellness experts seem to present themselves as being generally happy. They have completed a good portion of their wellness journey and are ready to help others, but they are also still on that journey so their followers know they are not alone. 


\section{Chapter 5: Discussion}

The research questions this study set out to answer were as follows:

RQ1: How do self-described wellness influencers on Instagram present wellness to their young adult audiences?

RQ1a: How do the products or paid content in these influencers' posts present wellness to their young adult audiences?

RQ2: What are the commonalities among the content streams of self-described wellness influencers on Instagram?

Overall the photographic research did highlight elements of the textual research, much like the Cavusoglu and Demirbag Kaplan (2017) research predicted. Seen through the lens of self-presentation theory, this study was guided towards looking at how the influencers portrayed themselves and their lifestyles.

\section{RQ1: How do self-described wellness influencers on Instagram present wellness to their young adult audiences?}

To answer the first research question, an insight found that wellness is indeed holistic and overwhelmingly represents holistic happiness. Happiness is inherently an elusive trait that has puzzled researchers for decades, if not hundreds, of years (McMahon, 2006). It is not a wonder why young adults today would want to seek out ways to achieve it. These influencers used a variety of ways to indicate happiness directly and indirectly to their followers.

Some elements these influencers used to promote happiness lied in photo content. Their photos were usually bright with some natural element including the outdoors, sunlight, or plants 
in the background. 126 out of 247 photos included some sort of natural element even if that element was not the emphasis of the photo.

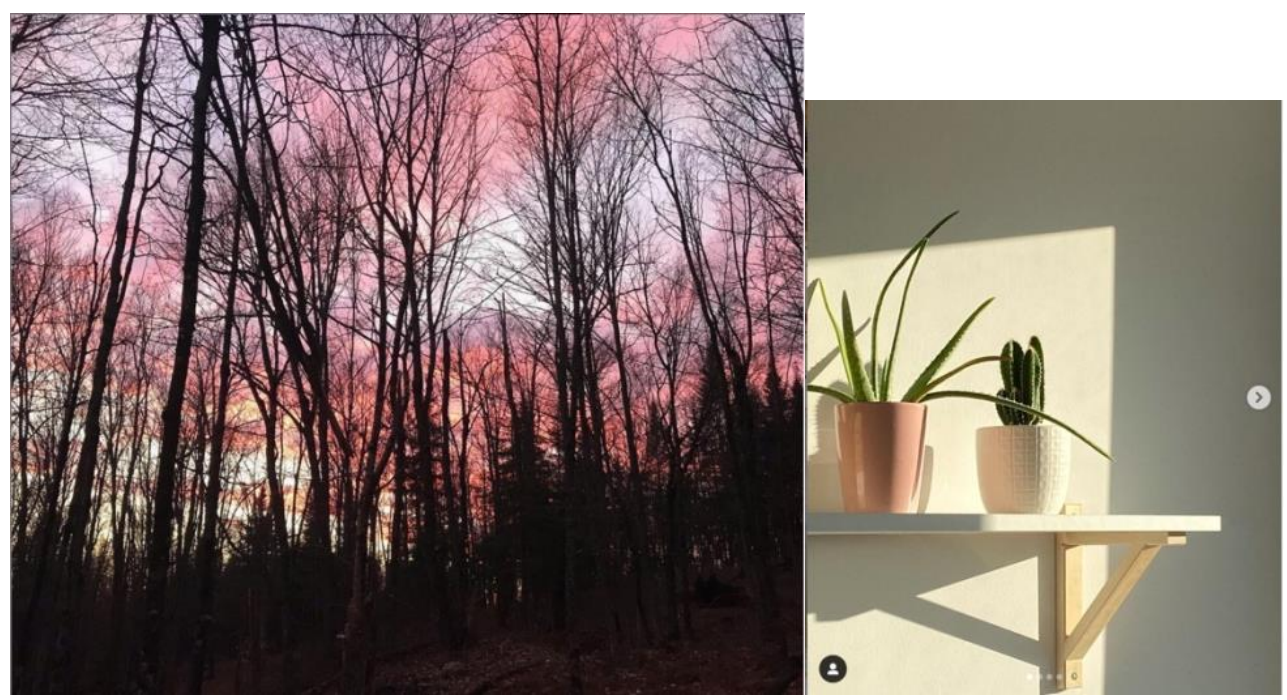

Humans are innately drawn to nature or living things because of the biophilia effect.

Chang et al. (2020) states that studies have shown the capacity of nature to improve attention, reduce stress and overall improve life satisfaction.

Most of the photos also included direct elements of happiness or comfort like smiles, dessert food, clothing, beds, or hot beverages. While food was a major player in many of these influencers' content, a vast majority of the food depicted was sweet, especially the desserts and breakfast food. 


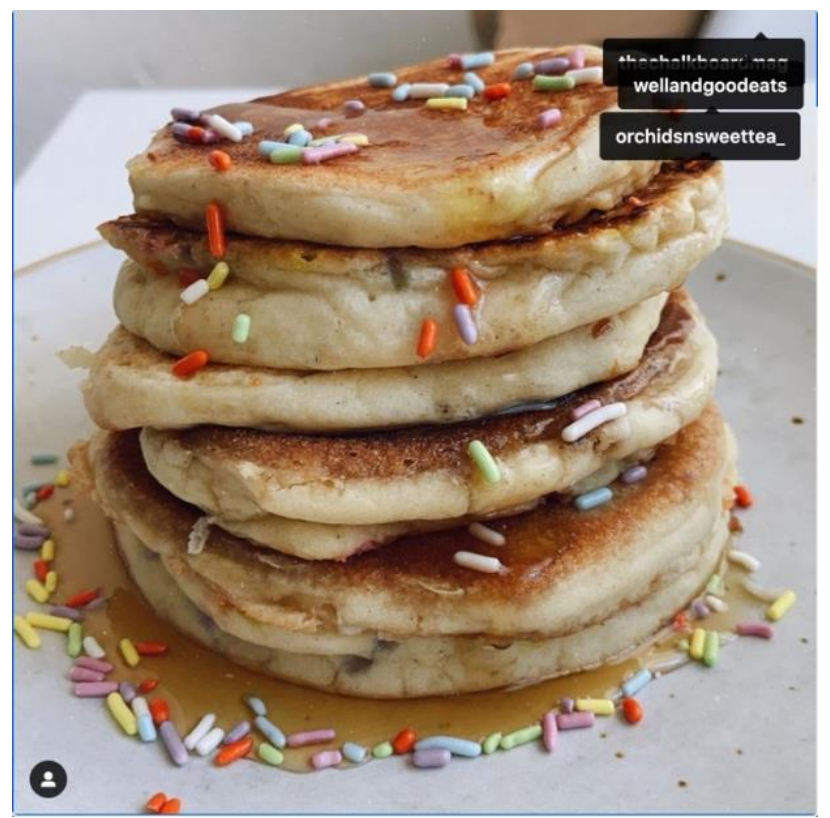

According to Freundlich (2021) from Health.com, sweets improve our mood because they are associated with long-standing traditions. Whether you got a cookie for doing your chores or ice cream for good grades, sweet food generally reminds us of those happy times.

Influencers are using these natural reactions to food or nature to not only generate happiness from their audience, but also to encourage their audience to choose happiness. Many posts included a demand or suggestion to engage in activities that promote happiness like going outside or including more fun food into a diet. These influencers abandoned the typical "skinny" lifestyle to turn the focus around on how items make a person feel instead of how things make a person look, encouraging the notion that wellness is an individual journey and negative external opinions do not matter. Most influencers went out of their way in the captions to illustrate that healthy practices such as healthy eating or being active does not have to be hard and should instead be enjoyable and provide a sense of good feeling.

Textual data also showed a happiness self-presentation theme. This is seen through a strong use of words like happy and grateful as well as a strong use of exclamation points and positive emojis including hearts and smiley faces. Textual tones besides informational are often 
used to promote happiness or action. These influencers used inspirational, grateful, excited, lighthearted or conversational tones in conjunction with important information. The word "happy" was the single most used word across all influencers and other words that fell under the 'happiness theme' were also strongly used such as "love" or "friend." For example:

"What puts a smile on your face!?:-,

;

What REALLY makes you happy!?:;

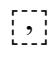

If this year has taught me anything, it's to lean in to all the things that make you feel good. (And on the flip side lean away from anything that doesn't). This goes for anything that takes up space in your life!!

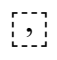

So tell me, what is it that makes you vibe on a higher vibration!?"

The strong use of a second person viewpoint was utilized to speak directly to the audience and encourage them to find happiness within whatever activity that influencer is promoting. Second person point-of-view was used to either spread love, happiness or gratefulness or to provide demands, suggestions or advice. Demands were typically used to encourage interaction through liking or commenting on the post while suggestions were about finding happiness through bettering of an environment or mental health. 


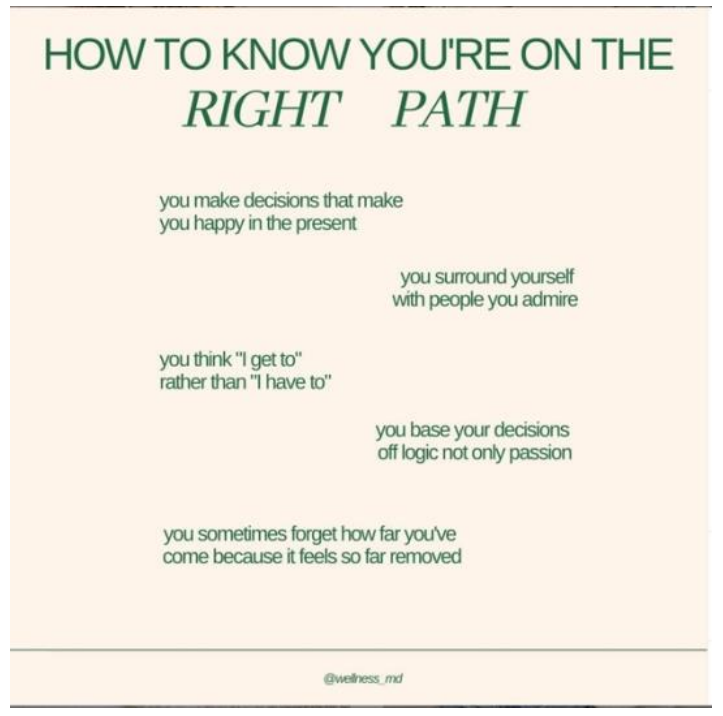

Happiness was split into three sub-categories including physical health, mental health, and clothing to determine the most important categories these influencers recommended to find happiness within. Happiness overall was a general theme that kept emerging throughout the research through the use of happy language, themes, and tones as well as the overwhelming appearance of smiles when the influencer was looking directly at the camera. Influencers often urged their followers to use their advice to bring happiness to their lives.

\section{Physical Health-Food}

Physical health was included under the happiness topic because while food was portrayed as healthy or healthier alternatives, it was also overwhelmingly sweet and was often a source of happiness for the influencer. The influencer would often write about how much she enjoyed creating or eating this food and the creation of the food was often dubbed as fun and simple, contradicting the commonly held viewpoint that healthy eating is boring, hard, and not tasty. The food was also often a source of good feelings by providing the influencer with some sort of benefit like relaxation or energy.

Food was overwhelmingly mentioned with 12 out of the 15 influencers posting about some sort of food. According to Veenhovan (2019), good health results in happiness and closely 
related to good health is healthy eating. His study shows a direct correlation between healthy eating and feeling happy. All of the influencers who posted about food choices were making alterations to their recipes to promote healthy eating. Common themes found among these kinds of posts include that eating well is a part of wellness, healthy eating can be easy, and that healthy eating can taste good. While focusing on healthy eating was an important part of this topic, these influencers also ensured that their food was fun and enjoyable further persuading their followers to find happiness in every part of life.

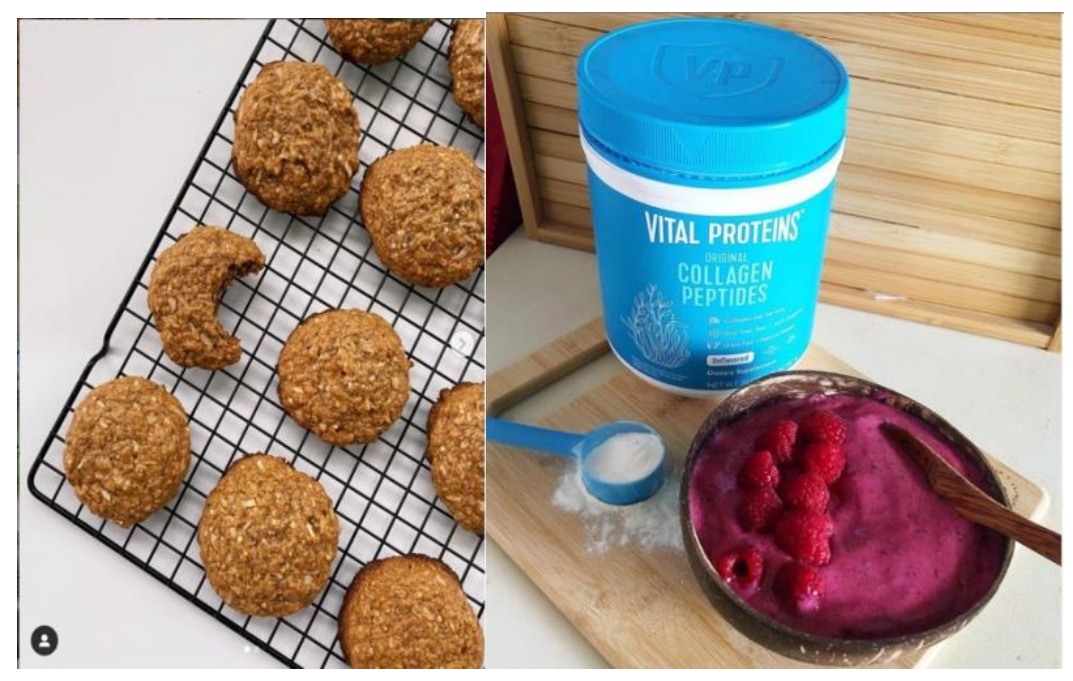

Desserts, sweet breakfast foods, and smoothies made up 52 out of the 99 food photos and were all staples in the study set indicating that wellness is about more than eating healthy. Wellness in this category seemed to be about finding ways to bring more happiness into life by treating mental stimuli with sweet treats while also finding what makes a person feel physically good by making those same treats better for the body.

\section{Physical Health-Body}

To quote Elle Woods from the movie Legally Blonde: "Exercise gives you endorphins. Endorphins make you happy. Happy people just don't shoot their husbands, they just don't," 
(Woods, 2001). While this is insightful, it is also backed by research. Zheng and Chen (2019) conducted a review of existing research on the link between physical activity and happiness and found an overwhelming and consistent relationship between physical activity and happiness. Physical activities such as working out or being active were portrayed as a source of happiness because influencers always related movement to how good it made them feel afterward. None of the influencers mentioned how movement made their body look.

While only three influencers focused on and posted traditional workouts, working out was consistently important in the textual analysis, and movement was present in most photo content. Exercise was the original code, but upon further review of both photo and textual content, movement was determined as a more suitable term since only three influencers directly mentioned the words coded under "exercise" in the textual analysis. Most influencers spoke about or showed an image of them engaging in some sort of activity or movement at least once throughout their content. These influencers promoted body movement in various ways from taking a walk to doing a full circuit at the gym. Some did not even mention the activity in the caption, but rather shared a picture of them playing a sport, being on the beach, or taking a hike highlighting a need for these activities to appear candid and natural (Miller \& Levine, 2019).

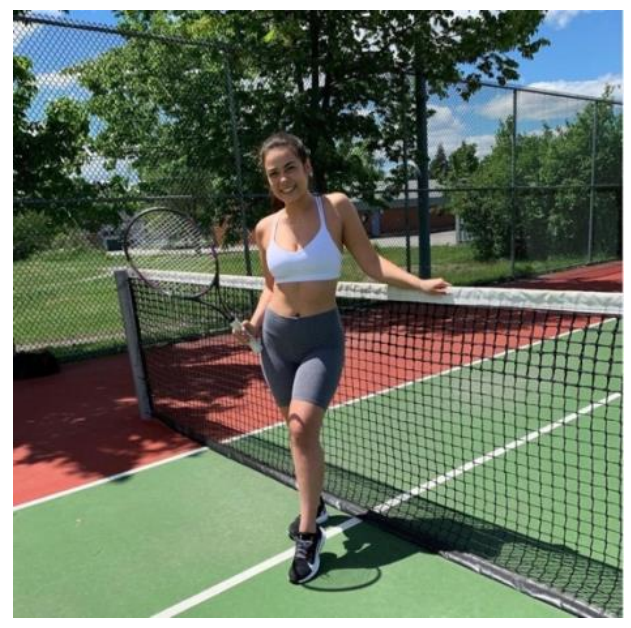


None of the influencers, however, focused on how the movement made them look, but rather encouraged their followers to focus on how the activity makes them feel. Physical activity was always promoted for its mental benefits or its ability to make someone physically stronger. For example, many encouraged their followers to take up yoga for its mental health benefits or to try a weighted workout to build up strength.

\section{Mental Health}

Mental health was included under the happiness topic because, while influencers would be open about mental health struggles, they would typically turn the conversation around to being happy. The way to improve mental health was depicted as being happy.

Most (13 out of the 15) of the influencers spoke candidly about mental health. Topics typically revolved around feeling isolated, depressed or overwhelmed. Influencers typically associated these with recent cultural shifts such as the racial injustice during the summer of 2020 or the COVID-19 pandemic. A Harris Poll determined, on behalf of the American Psychological Association (2020), that Gen Z was most impacted by the ongoing Mental Health Crisis that has been heightened by the COVID-19 pandemic. Gen $\mathrm{Z}$ adults are striving for help as 8/10 of them say they have not received the amount of emotional support they needed over the past 12 months. These influencers encourage their followers to find areas in life they can improve to make themselves happier. Practicing meditation, mindfulness, or self-care are popular ways these influencers showed how they make time for their own mental health. Slowing down is also a major practice as another common theme within the influencers' content was the need to notice things in everyday life and be grateful for what has been given. 


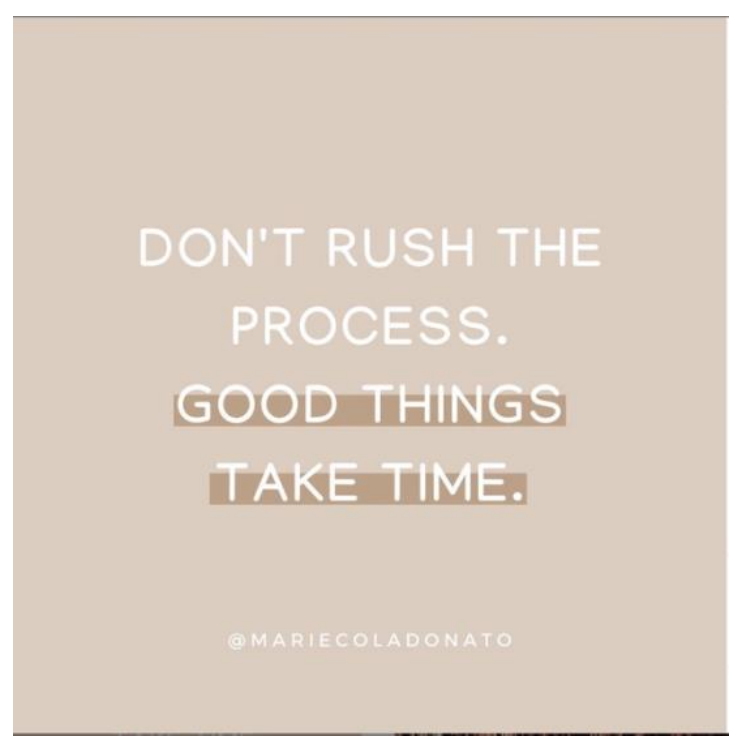

\section{Clothing}

Clothing was also a notable source of happiness in the research even though it was less prevalent in textual content. It was often tagged in photo content and consistently paired with bright, smiling images, and influencers would always mention how happy the clothing made them feel.

Ten out of the 15 influencers made it a point to mention what kind of clothing they were wearing or promoting. A surprising finding was that these influencers posted not only about the clothing they were wearing but also about how they felt about the clothing and, in turn, how the clothing made them feel. For example: 
"Flare pants are a thing this season and I'm glad I have so many of them ही"

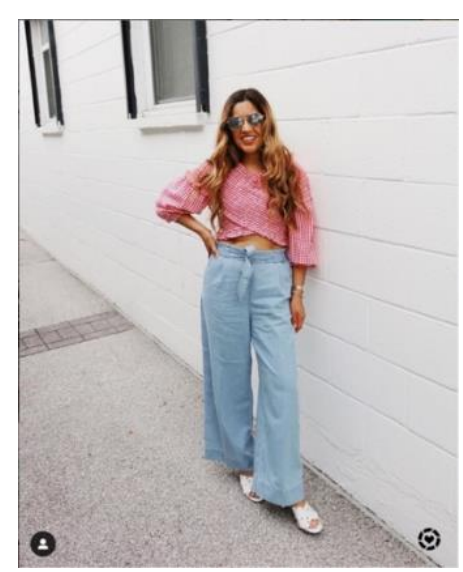

RQ1 Summary

These self-described wellness influencers presented wellness to their young adult audiences as a confusing, yet individual journey towards happiness. The influencers were selfappointed guides on this journey, and each influencer approached wellness differently highlighting the individuality of a wellness journey. These influencers show through their myriad of topics and lifestyle choices that wellness is not a recipe, but is rather a journey with many paths leading to a similar end. These lifestyle influencers posted about a variety of topics from clothing to food to working out yet all of their messages resulted in encouraging their followers to use their advice to find their own happiness.

RQ1a: How do the products or paid content in these influencers' posts present wellness to their young adult audiences?

Paid content furthers this narrative by presenting wellness as a way to feel better and to feel happy. Clothing, food, and supplements were the most common areas of promotion and all were presented as products that bettered life by providing ways to feel healthy and confident in one's own body. Clothing was an expression of personality and an inner source of happiness. 
According to DeLeire and Kalil (2010), leisure consumption of purchases, like clothing, can increase happiness due to its impact on social connectedness. Sharing these clothing choices with their followers can encourage connection between both the follower and the influencer and also encourages users to find happiness in another area of their life, their clothing.

Food and supplements, on the other hand, provided happiness through tasting delicious and sweet while also providing the body with extra nutrients to fuel it from inside out and provide good feelings. For example, the branded content that appeared the most were protein and collagen. Protein powder was typically added to provide benefit to a food that would typically not provide any benefit to the body. Collagen peptide powders were used for a lot of the same reasons of adding benefits and making a person feel physically better.

As mentioned before, the food that is posted is healthy but also overwhelmingly sweet. Most influencers choose to take a healthy spin on classic desserts by adding protein powder to brownies or substituting dairy for vegan options. Supplements and protein were also important parts of these influencers' journeys. Choosing to take care of their bodily health by promoting healthy eating habits and encouraging supplement or skincare use indicates that a healthy body is an important part of wellness, but the individuality of wellness suggests that no healthy body or journey will look the same. None of the influencers mentioned weight, muscles, or dieting. Followers were instead encouraged to take part in these healthy practices because they made a person feel good.

\section{RQ2: What are the commonalities among the content streams of self-described wellness influencers on Instagram?}

There was no single code that was common across every single influencer. No word, phrase, theme, filter, hashtag, or other studied content was mentioned across every influencer. In 
addition, no element was mentioned across every post made by a single influencer. The content these influencers posted was complex. For example, three out of the 15 influencers posted mainly exercise content, but also included other wellness topics in their content like mental health or fashion. One influencer focused her content on physical, bodily health speaking from her profession as a nutritional therapy practitioner, but she also notably spoke about other topics like her personal struggles with happiness and hair thinning. These influencers all touched a myriad of topics making wellness appear truly holistic as was found in the literature review (Mintel, 2020b).

The individuality among influencers' content made any commonalities found that much more important. Commonalities among influencers' content streams provided insight into how their self-presentations on Instagram relate directly to wellness since a specialization in wellness is what they all have in common. Influencers presented their content as both personal and guiding to their viewers using their self-presentations to solidify themselves as a wellness expert in their followers' minds. The focus on personal relationships touches on not only the personal relationsip between the influencer and their follower but also the personal relationship between that influencer as an individual and their own wellness journey. This highlights the wellness journey again as an individual experience that will be different for everyone. These influencers produce their content to serve as a guidebook to others looking for answers on how to live their life well. They set the example by expressing how they found their own way to happiness. Both of these insights portray the influencer as a relatable yet knowledgable guide on the subject.

\section{Personal Relationships}

One of the biggest themes found among the textual analysis showed a focus on the personal self. This focus was not necessarily always on the influencer, but rather how their 
personal journey can serve their followers. These influencers encouraged their followers to look within themselves for answers to their own wellness questions highlighting the wellness journey as an individual one. Many influencers encouraged followers to block out the wishes and demands of others to only focus on their sole mind, body and spirit connection. For example:

"I'm still figuring out what those tools are for me, but taking time (through walks, mediation, journaling, and just talking it out!) to truly think about what I love, what I want, and who I am is the only thing propelling me forward."

This poses a problem for the influencer moving forward if the wellness journey is truly individual since, theoretically, users would not have to turn to anyone to find their own wellness. Instead, the influencer has positioned themself as not only a wellness expert, but also as a friend to turn to during a potentially confusing and difficult time. This creates a sort of wellness community full of support for those going through their individual journeys.

The studied influencers made a conscious attempt to appear as natural and relatable as possible. They most often used first person singular language in captions with their use of personal pronouns such as I, me, mine, etc... This specific type of wording was used to humanize themselves which is a common influencer tactic (Mudambi \& Schuff, 2010). When they wrote from a first person singular point of view, they were often sharing personal details about themselves. These included surface level topics such as what they do, where they go, what they eat, and what they wear on a daily basis. However, they notably also included deeper topics such as their own personal goals and weaknesses. For example:

"I'm 22!

Wont sugarcoat it - this (like many other people) has been the worst year of my life so far. 
Went through a horrible emotional / physical trauma at the beginning of the year and less than 3 weeks later was forced into isolation due to COVID, where I developed disordered eating patterns while trying to perfect-away my problems.

My college graduation was cancelled, the country went through another racial awakening that showed me that my family isn't who I thought they were.

But being alone finally allowed me to start doing the work to focus more on who I am, what I wanted, and what I love about myself. I am grateful to have an amazing job, relationships, and this platform to use my voice.

Despite the pain of this year, I still got into 3 top business school programs (after taking the GRE while sick/emotionally devastated,) started my job as a marketer at YouTube/Google, and moved between soon to be four cities on accident. Most importantly, though, I started putting my opinions of myself before other people's.

Here's to more growth in my 22nd year of life!”

This weakness sharing has become a recent phenomenon in Instagram culture. An article from Rolling Stone (Jenke, 2020), refers to this as “vulnerability porn.” Instagram feeds are trending toward the bitterly realistic by showing unfiltered or realistic photos with long captioning illustrating the trials and tribulations of that influencer. The reasoning behind this new trend is to promote influencer authenticity. People are naturally interested in and attracted to stories of other people's lives due to their authenticity and they open up the door to conversation. These posts garner more engagement from audience members and provide a seemingly real human connection many are lacking in today's virtual pandemic world (O’Neill, 2020).

The photo content here provides more depth to this mainly textual insight. Photos and videos were not without their own faults much like the influencers themselves posting them. Images were natural and relatable with little use of obvious filtering. According to Vendemia and DeAndrea (2018), the more viewers think the images are modified the less influential or trusted 
the influencer becomes. Instead, these influencers opted for bright lighting and high saturation or contrast. This photo-editing choice is also backed by research since, according to Bakhshi et al. (2015), photos that increase exposure and contrast increase engagement and are more likely to be noticed due to their bright, eye-catching, yet natural colors.

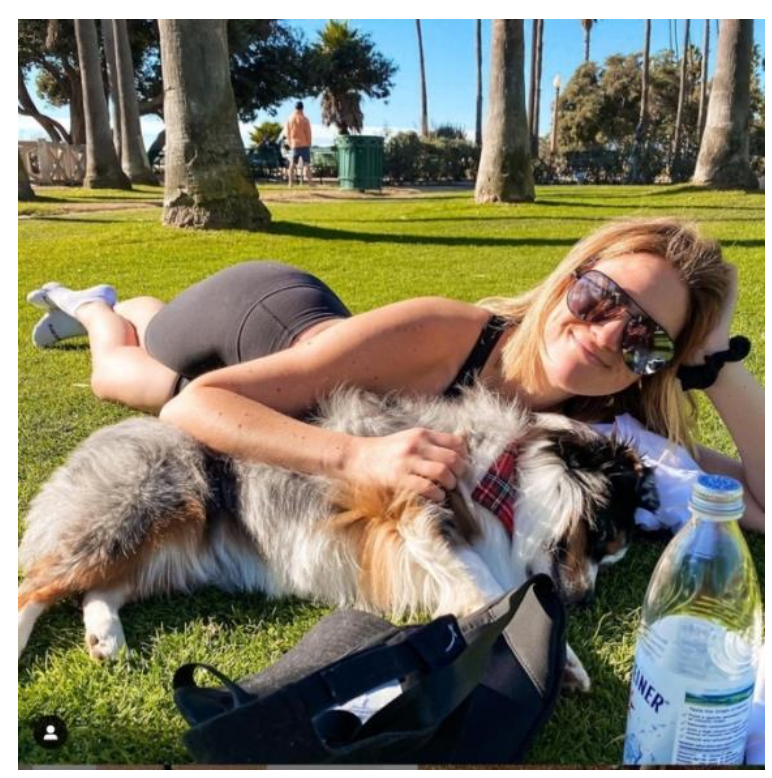

A study done by popular photo editing site Canva showed that the most popular Instagram filter in the world is Clarendon, a filter that enhances natural colors by brightening, highlighting, and intensifying shadows (Canva, 2020).

Many photos did have faults to appear natural, however, most of these were minimal. Some influencers posted with seemingly messy rooms and clothes strewn about while others made elements of their photo appear careless like the positioning of food tossed onto a plate or a towel wrinkled up next to a plate of dessert. 


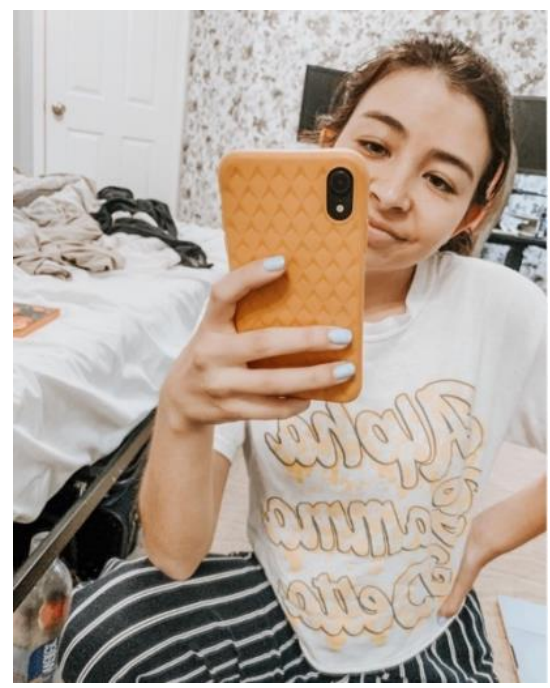

These influencers notably wore minimal to no makeup when they did appear in photos and their hair was usually made to look undone. However, these were never the focus of the post and the object that was in the center of attention was seemingly flawless. Food was always bright, the same size, and appetizing while photos of people were strategically posed to look candid.

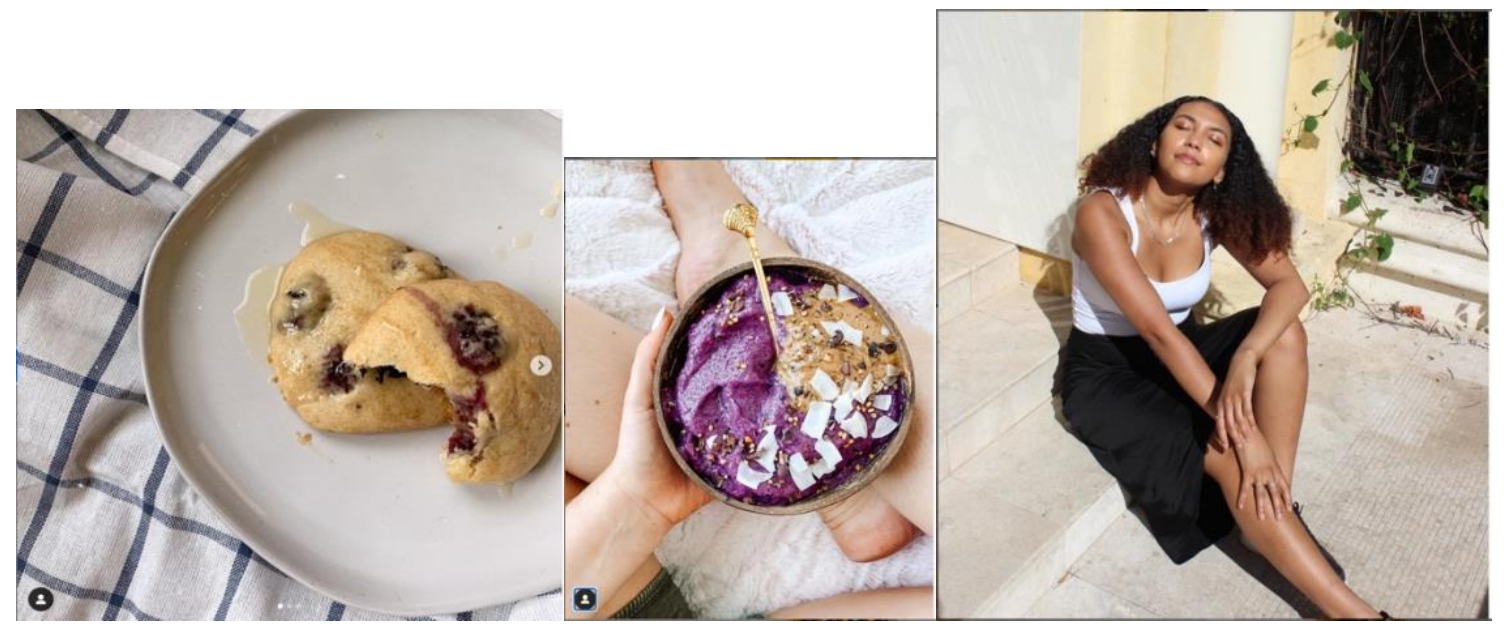

They appeared as perfect as they could get with their lifestyle still seemingly relatable

and in-reach. This is a new trend in Instagram culture as Generation $\mathrm{Z}$ is abandoning the perfect 'Instagram look" according to an article in The Atlantic. Perfect, posed photos are seemingly overdone in Instagram culture, and this generation prefers a more relaxed, laid back vibe that doesn't take hours of editing or searching for the perfect backdrop. Many are even going out of 
their way to make photos appear worse by posting less posed and more unfiltered candid images of themselves (Lorenz, 2019).

The Atlantic article highlights the need to appear candid in order to stand out from the overly-posed Instagram feed. For many, the post isn't even about the photo, but the photo is just a segway to venting in the comments section (Lorenz, 2019). The New York Times highlights the trend users as "captionfluencers" and illustrates how they may use a seemingly normal photo on Instagram to use the platform for it's popularity then post an extremely long caption. Instagram was primarily created for the use of photo sharing, but has now become one of the biggest overall storytelling platforms. A long, expansive caption detailing a hard story or lesson brings even more credibility and relatability to the influencer. They are seen as "deeper" than others who use the platform for over-edited photos with no real meaning or purpose behind the caption. This lets the influencer connect with their audience on a down-to-earth level (La Ferla, 2019).

The previous research is all to show that these influencers are going out of their way to make their content and themselves natural and relatable to their audience, two marketing traits that only influencers can carry because of the bonds they create with their followers (Tafesse \& Wood, 2020). The influencers often used their caption section to speak directly to their audience like peers, in fact, second-person was the second most used point-of-view from this study. They often used words that had a friendship connotation such as 'friends, guys, homies, lovelies, etc...' According to Enke and Borchers (2019), speaking to an audience as if they are peers increases that influencers credibility and authenticity, allowing for audiences to buy-in to what they are saying. Some influencers posed questions to their audience to prompt engagement and further create a personal connection between the influencer and follower. 
Personal relationships emerged as a theme because of the prevalence of relational wording and theme in the textual analysis as well as personal elements included in the photographic analysis. Influencers would mainly only speak about themselves or their followers directly and often indicated that the advice from others did not matter on a wellness journey. Wellness was portrayed as an individual journey that was different for everyone. Influencers were also often found directing advice or suggestions at their audience and also tended to include elements of themselves even when they were not the center of the posts. These influencers also tried to make their content seem as natural and relatable as possible by including natural elements and writing about personal moments. This focus on authenticity, credibility and personal relatability sets the stage for the next thematic section found in this research.

\section{A Guiding Mentality}

The purpose of this study is to understand 18-24 year-olds' definition of wellness. These influencers may also understand that wellness is a muddled term and have chosen to take on the role of wellness guide. They have positioned their content in such a way that followers see them as a trusted source of not only wellness information, but also a guide through a journey.

A guiding mentality was evident through the strong use of second person and audience direction. Influencers mainly spoke informationally about topics and presented themselves as nothing short of experts. Content was often guiding the audience toward a certain answer by either directly providing a solution to a problem presented in text or visually guiding the audience there. Photos had little background material and, if an influencer appeared in a post that was about something other than herself, she would often look away from the camera, not smile, not include her face, or only include a hand or leg in an effort to direct our attention to another part of the post. 
These influencers want their followers to know they practice what they preach, again enhancing their credibility so that followers would be willing to take their outsider advice on such a personal and individual topic as a wellness journey. Their content is rarely about them as a person and more about what they are doing or what activities they are engaging in at the moment. Their photo content usually highlights something else rather than themselves, but they often add a personal element to show they engage in that practice. For example, if the post was about a smoothie recipe, the photo would not only include the smoothie but also their hand holding the smoothie to show they have the intention of drinking it.

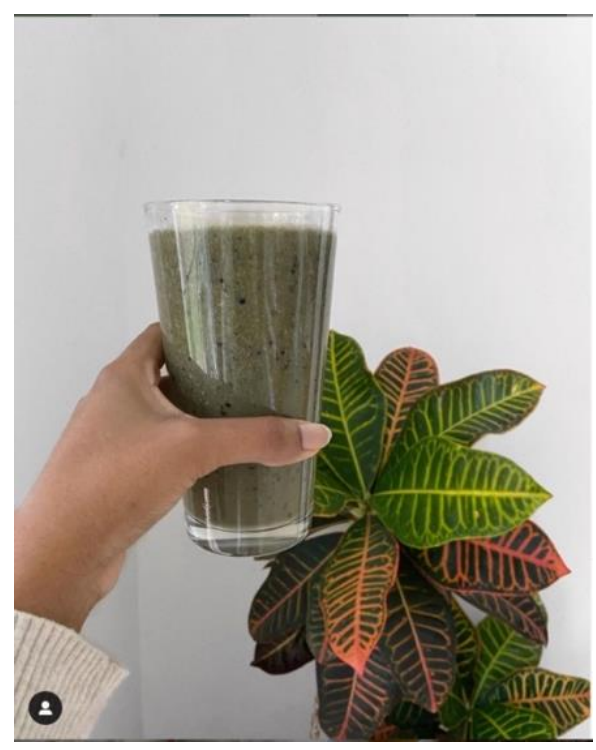

152 out of 247 photos included some sort of personal element. Another popular example would be the influencer posting about the outdoors. The photo would include a photo of them in the outdoors, but they would not be looking at the camera in order to keep the focus on the message. 


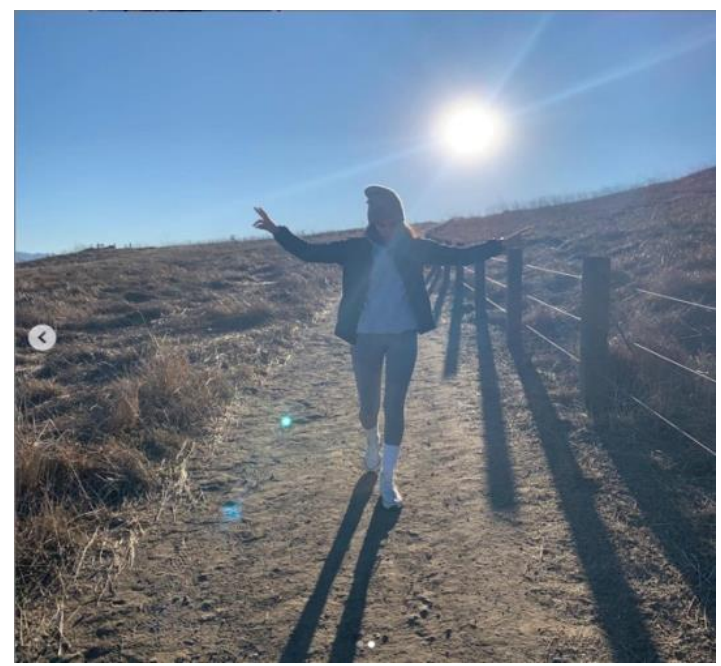

Another way these influencers establish themselves as a guide is by using the personal relationship they have created with their followers by sharing their own personal shortcomings. The way these influencers recognize weakness is very strategic because every instance where they recognize weaknesses they always have a way of overcoming them. These weaknesses are usually common issues relating to an individual's mental or physical state. For example, some common weaknesses these influencers included were about feeling anxious, having no motivation, or feeling tired. They often overcame these weaknesses by suggesting simple solutions like making a goal to be in the present, offering personal stories of how they get motivated, or making healthy eating easier. They mainly used first person singular wording here to build more credibility for themselves. For example:

“Intentions for 22 目

Well my birthday was actually 2 days ago but I was too busy eating all the yummy treats to post 쿱 융 My birthday is always a weird day. I get to see all my favorite people but also kind of always makes me anxious. I'm a very future oriented person and I KNOW 22 sounds young to a lot of you but every year I'm like "well why isn't my sh*t together??”. In some ways I feel like I'm still 12 years old but also simultaneously 45 if that makes sense to anyone???

So anyways, in light of making the most of 22 , here are my years intentions; 
1. Be more present. I've learned that true happiness is in the process not the destination. Constantly waiting for things to come together will never leave you satisfied because each time you reach a goal it's just another tick in your list and you look for the next. I need to work on this myself.

2. Put time into things that matter. If it makes you happy, it's worth the investment. Don't let other people tell you what does or doesn't look good on a resume. [-:

3. Tell the people around me I love them more.

4. Compliment strangers. If you are walking by someone and you think something nice, why keep it to yourself instead of maybe make their day. [-.:-

5. Read more. I want to try to read 1 book a month. Ambitious but writing it here to keep me accountable.

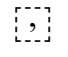

Can't wait to see what this year holds 回”

Long captions were used by the studied influencers to show they did indeed practice what they preach by showing them engaging in mentally and physically healthy activities like meditation or eating well as well as being grateful for having these opportunities to do so. The overall tone of most posts was informative yet in a kind way as if we are receiving advice from a friend.

While the journey itself may be personal to each one, the commonalities between these influencers' content show that each person is on their own journey together, and they can provide a kind of motivational support through sharing their own journey that resonates with others.

\section{Limitations}

This research has a subjectable nature since it included interpreting photos with limited text and hashtags. I did not interview these influencers and are unaware of the intended meaning of their posts. This study reflects my interpretation as a researcher.

This study was only able to utilize the Upfluence database for 48 hours since it is being conducted by an independent researcher rather than a company. Due to the inability to access 
larger influencer databases, this study has a small study set of 15 Instagram influencers. Because of this, research will be concluded after sampling these 15 influencers rather than seeking saturation. I am unable to know if this data set is representative of all wellness influencers and the posts themselves may not be representative of 18-to-24 year old's understanding of wellness since following does not necessarily mean agreement.

This research also does not examine the truthfulness of influencer claims. Selfpresentation theory denotes that individuals will portray a better and more agreeable version of themselves to match their audience's preferences. However, this study will not have the ability to follow these influencers into their daily lives to examine if what they post on Instagram is truly a representation of their wellness journey. Paid sponsorships were also difficult to determine since none of the influencers included "ad" in their posts. This research did not identify if these brand sponsorships were truly paid or the truthfulness of these influencers' claims about sponsored items.

Another limitation of this study is the events of the year it was conducted. During the first round of data gatering, the world has been battling the coronavirus for nine months which will likely change the common definition of wellness. The second round of data gathering set six months prior also held the coronavirus challenges, and the United States was dealing with great social unrest. These events most likely contributed to a shift in priorities for these influencers.

\section{Areas for Further Research}

This study is limited to studying the pictorial and textual elements of an Instagram post. Future research could include the elements of audience interaction including comments and likes to determine which posts are accepted or rejected by the audience. The addition of the audience offers a new pathway for research using the self-presentation method. The role of a wellness 
community in a wellness journey could also be studied since it was found to exist in Instagram. Other non-static social media platforms where Gen $\mathrm{Z}$ influencers are prominent could also be studied including YouTube and TikTok. The introduction of video streaming can allow for a new use of the self-presentation method.

While this study provides valuable research on the perceptions of the wellness term, more research can also be done to determine how young adults carry out their wellness journey. Factors such as interaction with others, diet, exercise and mental health awareness could be included as part of a future study. Other terms closely related to wellness such as self-care and health could help guide future research in wellness journeys. 


\section{Chapter 6: Conclusion}

This study set out to understand how 18-24-year-old young adults define wellness by studying wellness influencers' content streams. The self-presentation theory was used to determine how wellness influencers presented themselves and their "wellness lifestyle" to their audience. Wellness has been a rising trend with young adults, yet it also seemed to have a muddled meaning. Many studies have determined that wellness was a holistic approach to health, but this study dived further into understanding what that really means and what young adults really want when they say they are searching for wellness.

Research found that these influencers presented themselves as a guiding, friendly personality, much like previous influencer research suggested. However, this is important within the wellness context because it provided some insight into the wellness journey itself. The wellness journey needs a friendly guide because it can be confusing and frustrating when one wants to live their life well but does not understand the meaning of wellness. These influencers have put a portion of their lives on display to serve as an example of how they have found wellness within their own lives. While influencers stress that their methods may not work for everyone since every wellness journey is different, wellness does end in the same goal for everyone, and that is happiness.

Wellness has puzzled researchers because happiness has puzzled researchers. Happiness is extremely personal and looks different for everyone involved, a striking comparison to the wellness narratives found in the research. Influencers not only presented themselves as happy, but they also encouraged their followers to find happiness in their own everyday lives whether it be by standing up for yourself or making yourself dessert. Humans have been searching for the 
key to happiness since the beginning of time and this wellness trend is another iteration of that search. Wellness being defined as holistic health is accurate, but it is not complete. The reason this research found that young adults prioritize holistic health is to feel good from the inside out by acknowledging the need of their mind, body and soul. They want to feel good and healthy because that makes them happy and who doesn't want to be happy?

Future researchers, marketers, advertisers, inventors, or any other sector dealing with wellness can use the results of this research to conclude that young adults today are not fully happy. They are seeking out products or people that will guide them to living a life that is happier or feels better than the one they already have. While this research may not assist in creating limitations or laws on wellness products, this study does provide important insight that the happiness can possibly be found within by focusing on a person's individuality. 


\section{Appendix}

\begin{tabular}{c|l|r|r|r|}
\multicolumn{2}{c}{ Influencer List } & \multicolumn{1}{c|}{ A } & \multicolumn{1}{c|}{ C } & \multicolumn{1}{c|}{ D } \\
\hline \hline 1 & Influencer & Followers & Engagement Rate & Audience 18-24 \\
\hline 2 & Emily Escobar & 1,090 & $20.43 \%$ & $37 \%$ \\
\hline 3 & Sanja Jerkovic & 1,421 & $19.93 \%$ & $58 \%$ \\
\hline 4 & The Healthy Avo & 18,000 & $5.52 \%$ & $42 \%$ \\
\hline 5 & Baseline Gravity & 3,722 & $2.99 \%$ & $40 \%$ \\
\hline 6 & Marie Coldadonato & 3,844 & $10.97 \%$ & $57 \%$ \\
\hline 7 & Wellness Alexis & 6,147 & $9.92 \%$ & $40 \%$ \\
\hline 8 & The Daily Carmen & 8,673 & $3.11 \%$ & $60 \%$ \\
\hline 9 & faith_n_fit & 11,300 & $2.21 \%$ & $53 \%$ \\
\hline 10 & Sophia Rose & 31,800 & $11.21 \%$ & $39 \%$ \\
\hline 11 & Kate Craig & 65,600 & $7.22 \%$ & $56 \%$ \\
\hline 12 & Gabriella Lopardo & 21000 & $4.93 \%$ & $38 \%$ \\
\hline 13 & Noam Raiter & 16700 & $7.12 \%$ & $40 \%$ \\
\hline 14 & Sanam Tahan & 10000 & $8.50 \%$ & $40 \%$ \\
\hline 15 & Sarah King & 3,273 & $5.39 \%$ & $48 \%$ \\
\hline 16 & Ba Hughes & 2593 & $8.66 \%$ & $45 \%$ \\
\hline
\end{tabular}

\section{Influencer Bios}
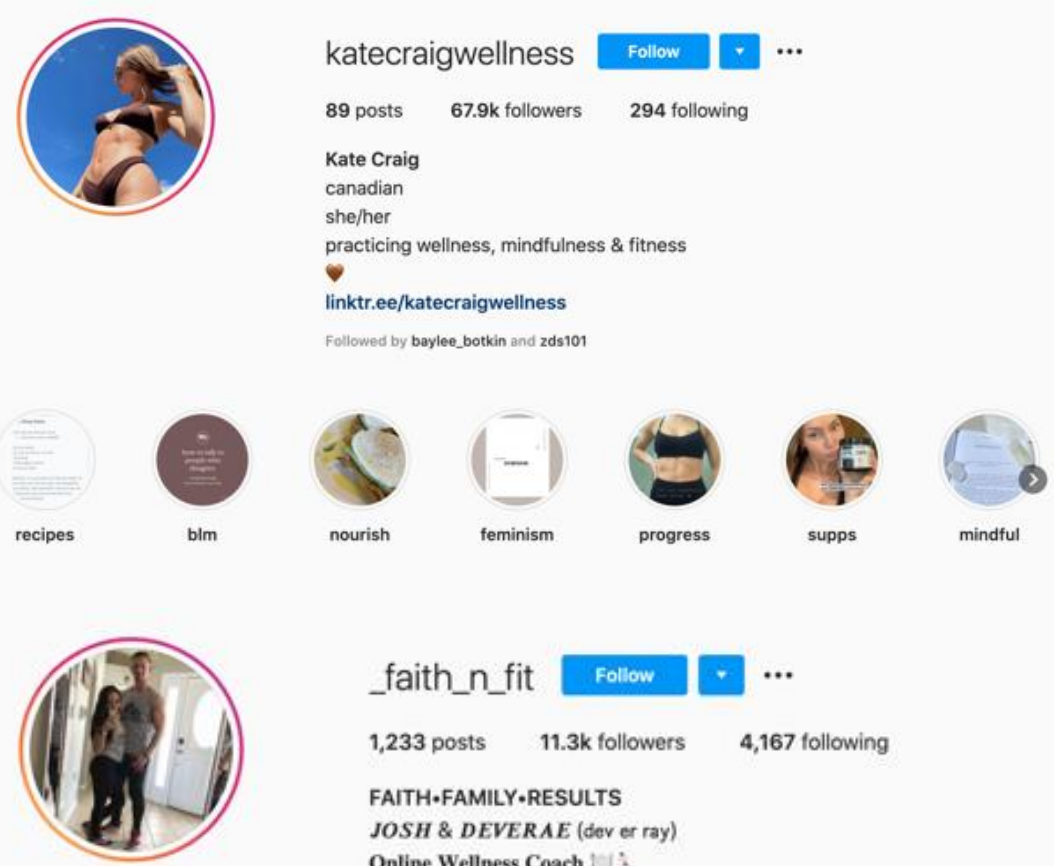

faith_n_fit Follow..-

1,233 posts $\quad 11.3 k$ followers $\quad 4,167$ following

FAITH•FAMILY•RESULTS

JOSH \& DEVERAE (dev er ray)

Online Wellness Coach $11: \therefore$

Wife $>$ Mom $>$ Boss

Let's create healthy lifestyles through

WHOLE LIFE SUCCESS File

montano24.goherbalife.com/en-us

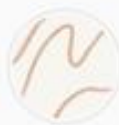

Back Work.

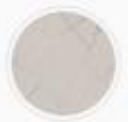

Meals \& S...

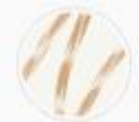

Weight Loss

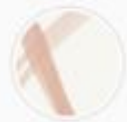

Leg Worko...

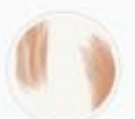

Project Yo...

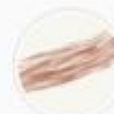

Arm Work...

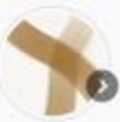

MStation 

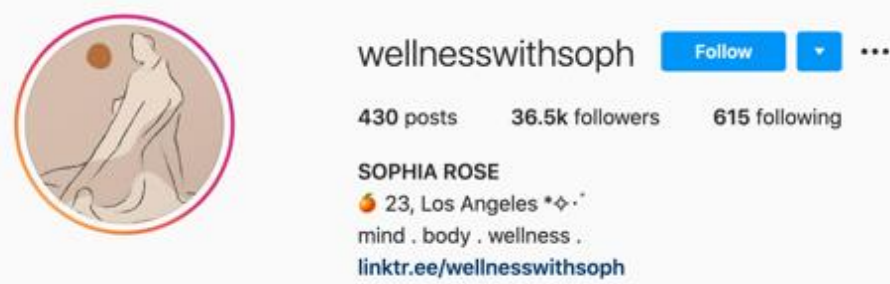

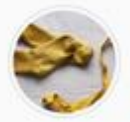

november

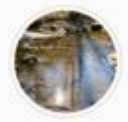

october

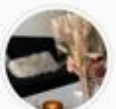

HOME

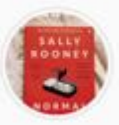

BOOKS

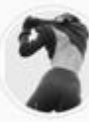

FITS

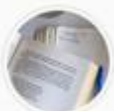

JOURNAL

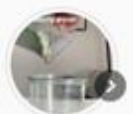

POUR UP
曲 Posts
B IOTV
(8) TAGGED

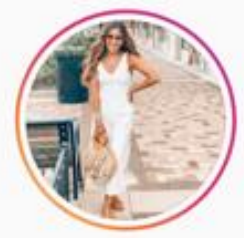

thedailycarmen Follow $-\ldots$

917 posts $\quad 8,622$ followers $\quad 2,028$ following

C ARMEN

Wellness for a balanced life. Home organizer, Minimal style $\$$, Mom \$, STL ? www.thedailycarmen.com
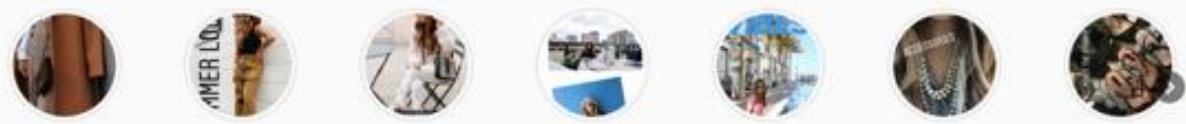

FALL $\approx$

Fav Looks

Monochro...

Collabs

SUMMER -

ACCESORI.

Shoes

E POSTS OREELS OIOTV DT TAGQED

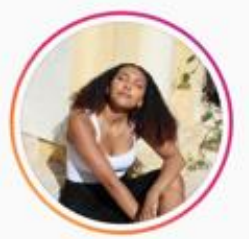

wellnessalexis Follow $-\ldots$

63 posts

6,325 followers

610 following

alexis

ur too smart to be on a diet

21

linktr.ee/wellnessalexis

Followed by hollyenowski
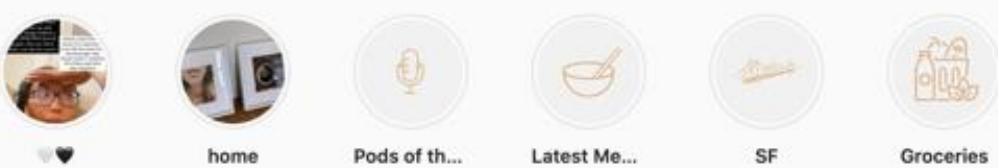

(2)

Pods of th...

Latest Me...

SF

Groceries

Q\&A

霜 posts 


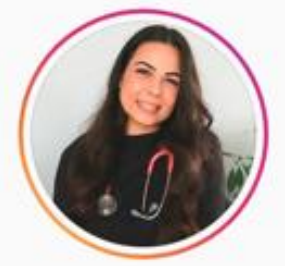

\section{mariecoladonato Follow $-\cdots$ \\ 38 posts \\ 4,431 followers \\ 2,449 following}

MARIE, RN / I Health \& Wellness

Soon to be BSN

MTL 9

Watch my new YouTube video!

youtu.be/0XeWB5yT854

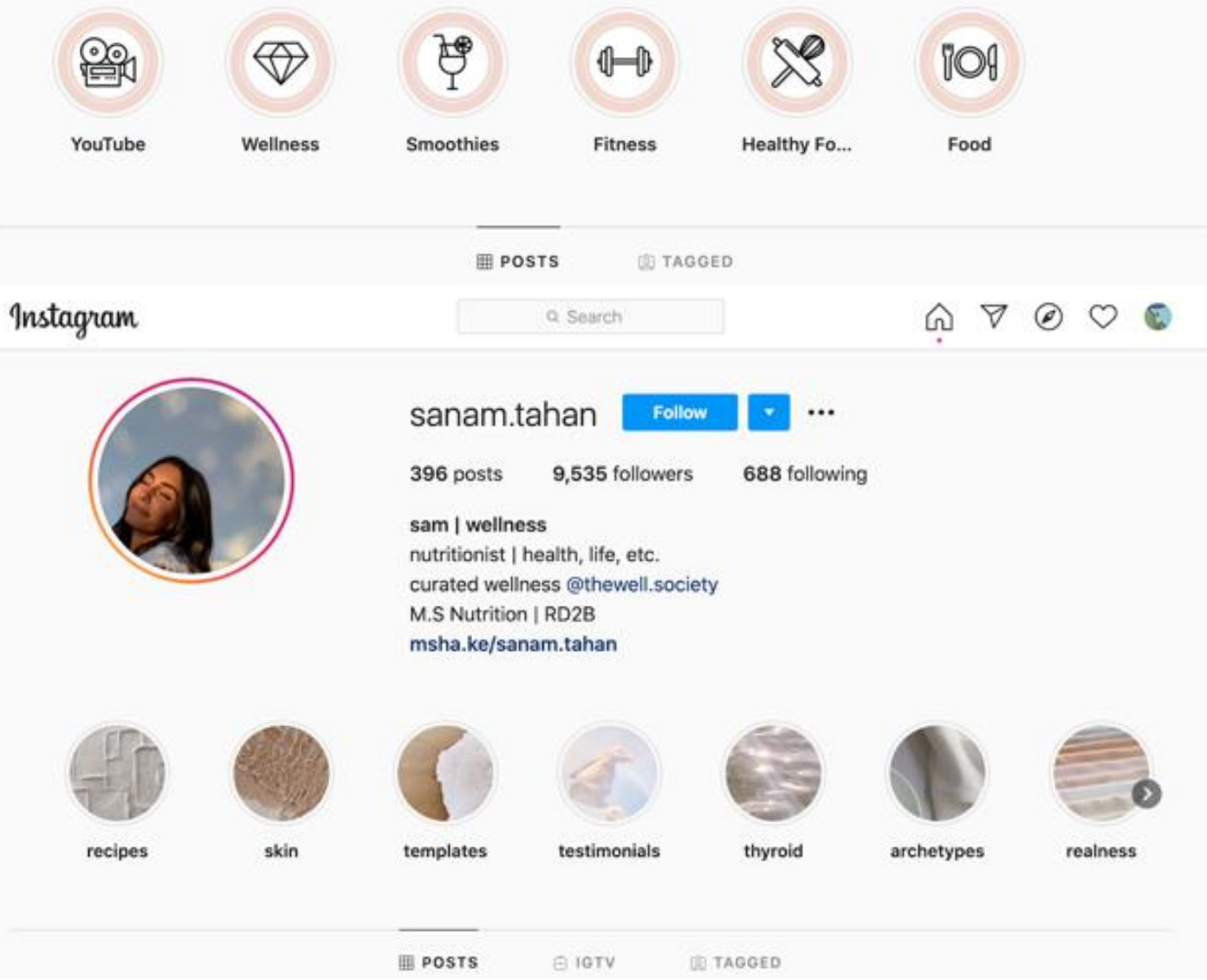




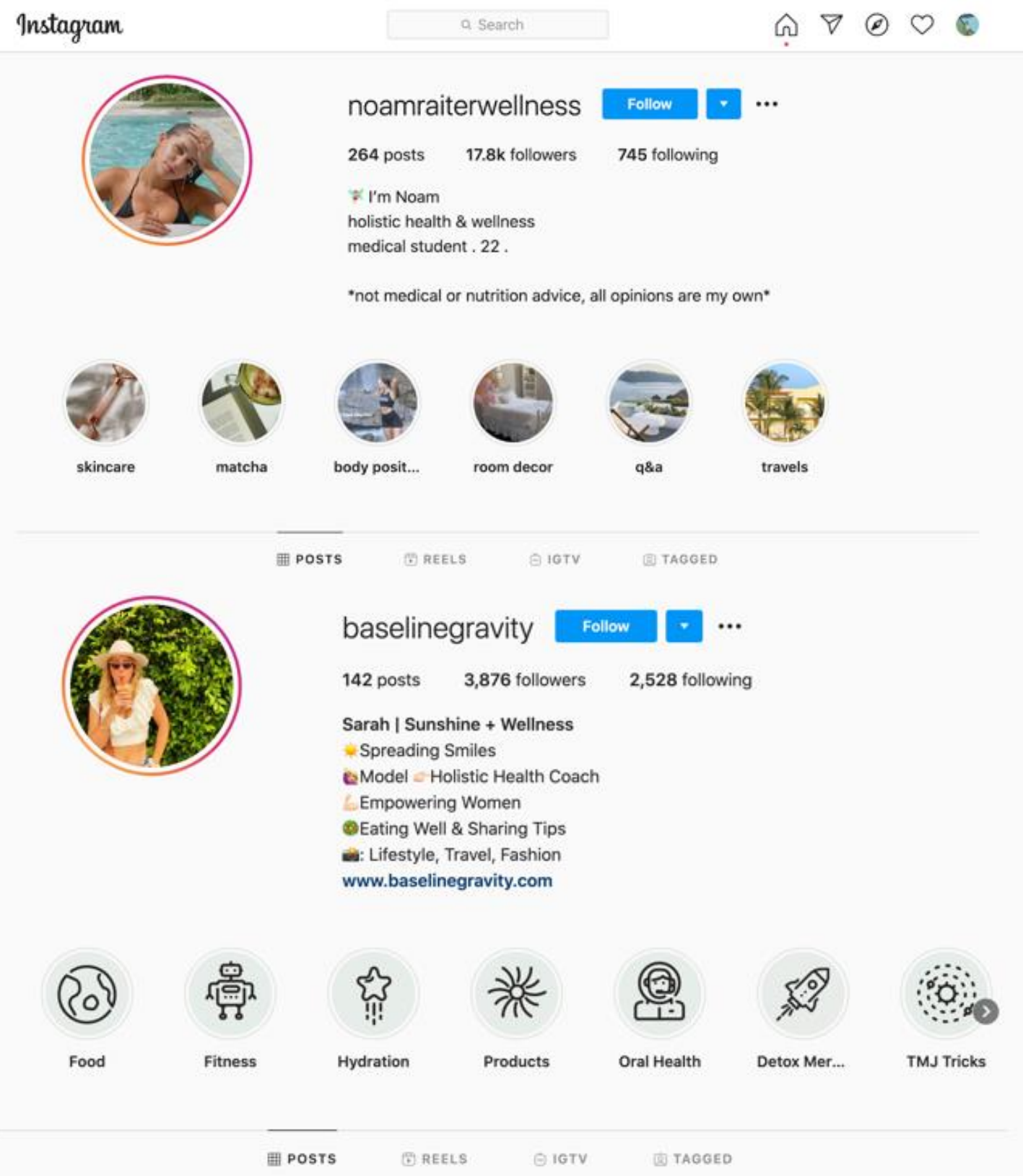




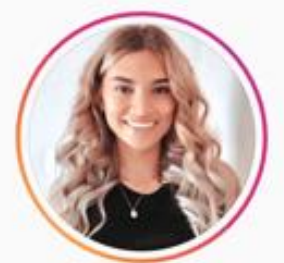

\section{_sjthekin Follow $\quad$...}

231 posts $\quad 1,456$ followers $\quad 972$ following

MSanja Jerković • RKIN

- I help people find the potential within their body -

Registered Kinesiologist

BHSc.Kin | Dog Mom \$र| Health Promoters:

@@trainsmartwellness

trainsmartwellness.janeapp.com/locations/trainsmart-wellness/book

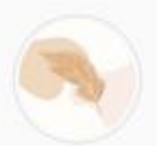

Iife

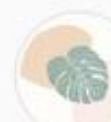

11tness

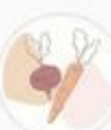

eats

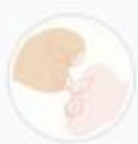

bootcanp
부내ำ

travels

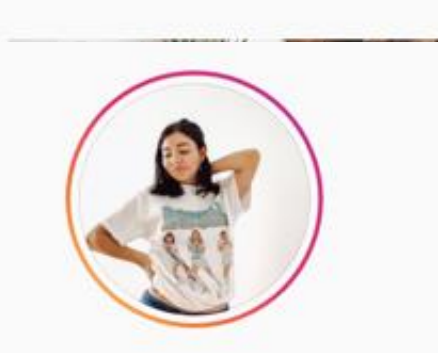

橉 POSTS

emily_escobar_

348 posts

1,123 followers

Follow

Emily

iSF

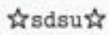

@alphagamsdsu 0

Co-Founder \& Consultant @minimalist.media 0

Wellness \& Health Advocate $\bullet$

linktr.ee/emilyescobar

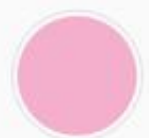

Fits

San Franci.

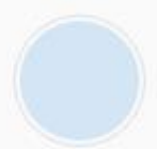

Health

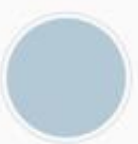

Bestie

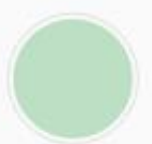

Outfits

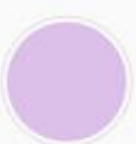

AGD

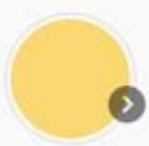

Family

娄POSTS FEELS TAGGED 


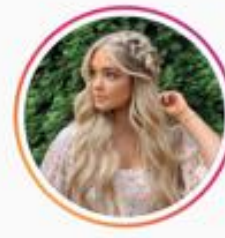

thehealthyavo follow ...

400 posts $\quad 18 \mathrm{k}$ followers $\quad 592$ following

The Healthy Avo

Health / Food / Wellness

Plant based bites of

Healthy living :

\#thehealthyavo

$1 c b 0914 c 64 a 05752$ ed3a5504294cbafd2263c1ce4f6f14b68a

linktr.ee/thehealthyavo
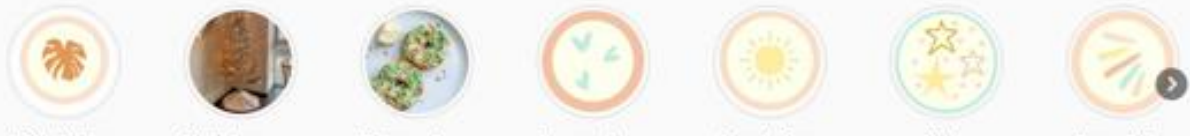

Little things

Christmas ....

Discount c...

Fav produ...

Lunch time

Style

Smoothies

III POSTS T) REELS DO TAOOED 


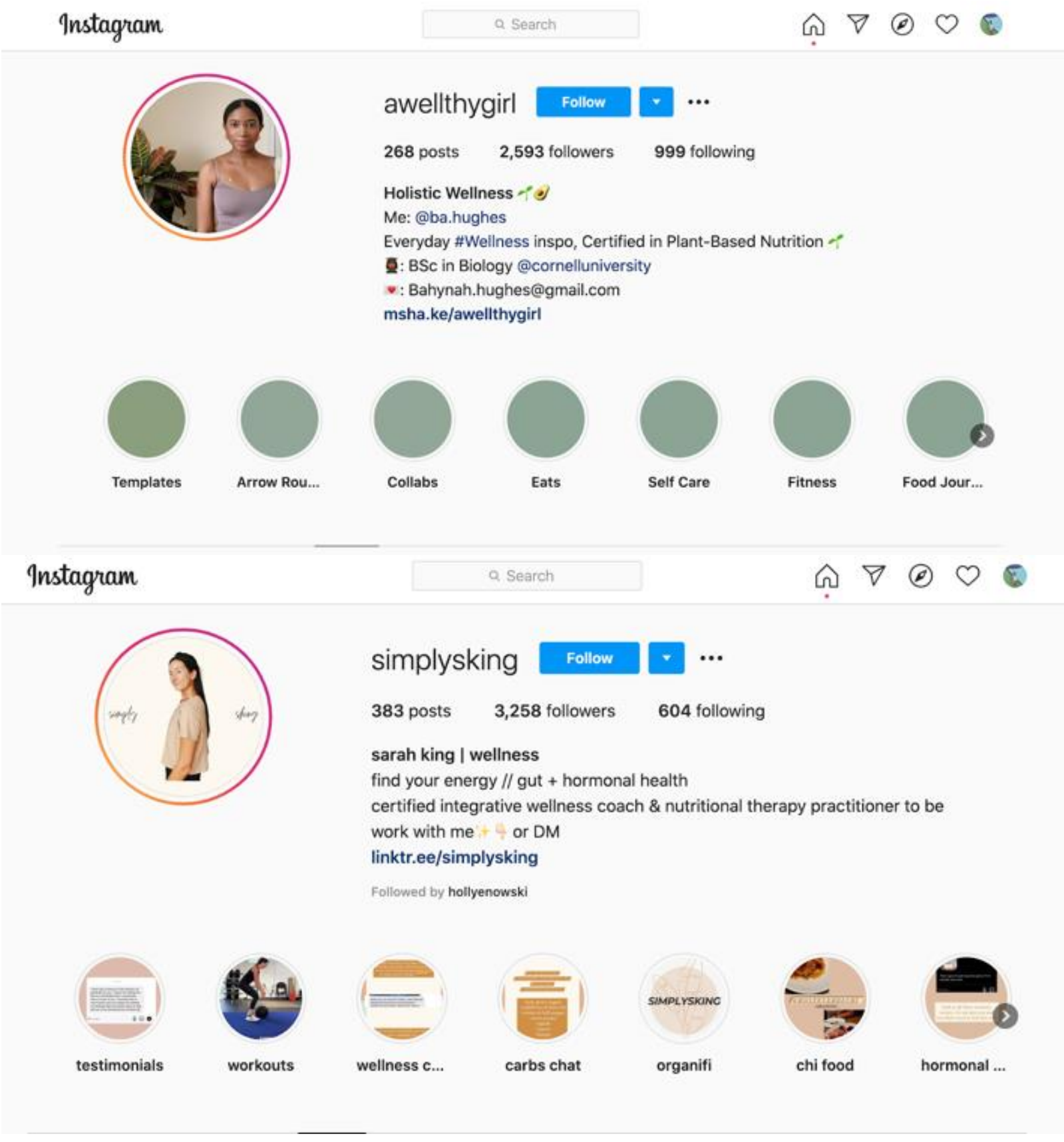



Instagram
Q Search
$\Omega \nabla \odot \odot$

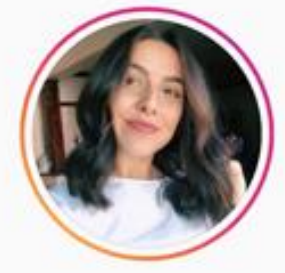

\section{lifebygabb Follow,$\cdots$ \\ 435 posts $\quad 21.6 k$ followers $\quad 743$ following}

food, wellness \& life

24 years young $W$

good food, gratitude, self care lovin, embracing life $\&$ sharing it along the way 0 linktr.ee/LifeByGabb

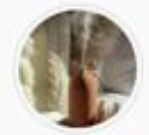

home

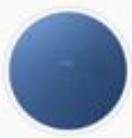

soul

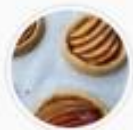

food

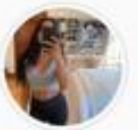

body

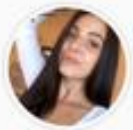

skin

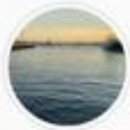

life

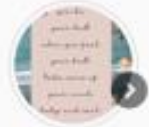

quotes

\section{Photo Content}

\begin{tabular}{|c|c|c|c|c|}
\hline & A & B & c & D \\
\hline 1 & & & & 247 \\
\hline 2 & Personal Elements & & & 152 \\
\hline 3 & & Looking at camera & & 47 \\
\hline 4 & & & Smiling & 36 \\
\hline 5 & & & Not Smiling & 11 \\
\hline 6 & & Not looking at camera & & 48 \\
\hline 7 & & & Smiling & 18 \\
\hline 8 & & & Not Smiling & 29 \\
\hline 9 & & Hand & & 33 \\
\hline 10 & & Friends & & 26 \\
\hline 11 & & No head & & 11 \\
\hline 12 & Natural Elements & & & 126 \\
\hline 13 & & Outdoors & & 49 \\
\hline 14 & & Plants & & 35 \\
\hline 15 & & Sunlight & & 20 \\
\hline 16 & & Living Creature & & 8 \\
\hline 17 & & Sunrise/Sunset & & 6 \\
\hline 18 & & Ocean/Pool & & 5 \\
\hline 19 & & Wood & & 3 \\
\hline 20 & Food/Drink & & & 99 \\
\hline 21 & & Dessert & & 27 \\
\hline 22 & & Breakfast & & 13 \\
\hline 23 & & Smoothie & & 12 \\
\hline 24 & & Hot Beverage & & 9 \\
\hline 25 & & Snacks & & 9 \\
\hline 26 & & Lunch/Dinner & & 8 \\
\hline 27 & & Water & & 8 \\
\hline 28 & & Drink & & 6 \\
\hline 29 & & Salad & & 4 \\
\hline 30 & & Alcohol & & 2 \\
\hline 31 & & Soup & & 1 \\
\hline 32 & Sponsored Product & & & 67 \\
\hline 33 & & In use/ no packaging & & 48 \\
\hline 34 & & In use/ packaging & & 7 \\
\hline 35 & & Not in use/ in packaging & & 12 \\
\hline 36 & Misc & & & 121 \\
\hline 37 & & Clothing & & 47 \\
\hline 38 & & Wording & & 22 \\
\hline 39 & & Bed/Room Decor & & 19 \\
\hline
\end{tabular}




\section{References}

American Psychological Association. (2020, October 20). Stress in America 2020 Survey Signals a Growing National Mental Health Crisis. https://www.apa.org/news/press/releases/2020/10/stress-mental-health-crisis

Audrezet, A., De Kerviler, G., \& Moulard, J. G. (2018). Authenticity under threat: When social media influencers need to go beyond self-presentation. Journal of Business Research, $117,557-569$.

Baker, S. A., \& Rojek, C. (2020). The online wellness industry: why it's so difficult to regulate. The Conversation.

Bakhshi, S., Shamma, D., Kennedy, L., \& Gilbert, E. (2015, April). Why we filter our photos and how it impacts engagement. In Proceedings of the International AAAI Conference on Web and Social Media (Vol. 9, No. 1).

Barreto, A. M. (2014). The word-of-mouth phenomenon in the social media era. International Journal of Market Research, 56(5), 631-654.

Baumeister, R. F., \& Hutton, D. G. (1987). Self-presentation theory: Self-construction and audience pleasing. In Theories of group behavior (pp. 71-87). Springer.

Brennen, B. (2017). Qualitative research methods for media studies (2nd ed.). Routledge.

Cartwright, M. (2020, November 1). Roman Baths. Ancient History Encyclopedia. https://www.ancient.eu/Roman_Baths/ 
Casaló, L. V., Flavián, C., \& Ibáñez-Sánchez, S. (2020). Influencers on Instagram: Antecedents and consequences of opinion leadership. Journal of Business Research, 117, 510-519. https://doi.org/10.1016/j.jbusres.2018.07.005

Cavusoglu, L., \& Demirbag-Kaplan, M. (2017). Health commodified, health communified: navigating digital consumptionscapes of well-being. European Journal of Marketing, 51(11/12), 2054-2079. https://doi.org/10.1108/ejm-01-2017-0015

Cederstrom, C., \& Spicer, A. (2015). The Wellness Syndrome. Polity Press.

Chang, C. C., Cheng, G. J. Y., Le Nghiem, T. P., Song, X. P., Oh, R. R. Y., Richards, D. R., \& Carrasco, L. R. (2020). Social media, nature, and life satisfaction: global evidence of the biophilia hypothesis. Scientific reports, 10(1), 1-8.

Chua, T. H. H., \& Chang, L. (2016). Follow me and like my beautiful selfies: Singapore teenage girls' engagement in self-presentation and peer comparison on social media. Computers in Human Behavior, 55, 190-197. https://doi.org/10.1016/j.chb.2015.09.011

DeLeire, T., \& Kalil, A. (2010). Does consumption buy happiness? Evidence from the United States. International Review of Economics, 57(2), 163-176.

Djafarova, E., \& Trofimenko, O. (2018). 'Instafamous' - credibility and self-presentation of micro-celebrities on social media. Information, Communication \& Society, 22(10), 14321446. https://doi.org/10.1080/1369118x.2018.1438491 
Enke, N., \& Borchers, N. S. (2019). Social media influencers in strategic communication: A conceptual framework for strategic social media influencer communication. International Journal of Strategic Communication, 13(4), 261-277.

Euromonitor International. (2020, June). The Coronavirus Era: Wellness Redefined. World Advertising Research Center.

Forrester, J. (2020, September 22). Three-Quarters of Instagram Influencers Hide Advertisement Disclosure in Posts, According to Awin. [Talking Influence]. https://talkinginfluence.com/2020/09/22/three-quarters-of-instagram-influencers-hideadvertisement-disclosure-in-posts-according-to-awin/

Foucault, M. (2020, September 6). Technologies of the Self - Lectures at University of Vermont in October 1982. Michel Foucault, Info. https://foucault.info/documents/foucault.technologiesOfSelf.en/

Freundlich, N. (2013, September 12). The Reason Why Sweets Lift Your Spirits. Health.Com. https://www.health.com/mind-body/the-reason-why-sweets-lift-your-spirits

Geometry Global \& gen.video. (2017, June). The Influence of Influencers. https://drive.google.com/file/d/0B8uin-AAtdr-bER6ZVdyMjkxblk/view

Goffman, E. (1959). The Presentation of Self in Everyday Life (1st ed.). Anchor. https://books.google.com/books?hl=en\&lr=\&id=TlIAzT5uTIC\&oi=fnd\&pg=PA120\&ots=IuDabhKlh7\&sig=fr3tivXmv6rJKFiDfNh809zXqw\#v=onepage $\& q \& f=$ false 
Gómez, A. R. (2019). Digital Fame and Fortune in the age of Social Media: A Classification of social media influencers. aDResearch: Revista Internacional de Investigación en Comunicación, (19), 8-29.

Goldhill, E. (2018, June). How rethinking qualitative research can help brands understand Generation Z. World Advertising Research Center. https://www-warccom.proxy.mul.missouri.edu/content/article/bestprac/how-rethinking-qualitativeresearch-can-help-brands-understand-generation-z/122290

Glaser, B. G., \& Strauss, A. L. (2017). Discovery of grounded theory: Strategies for qualitative research. Routledge.

Global Wellness Institute. (2018, October). Global Wellness Economy Monitor. https://globalwellnessinstitute.org/wpcontent/uploads/2019/04/GWIWellnessEconomyMonitor2018 042019.pdf

Haenlein, M., Anadol, E., Farnsworth, T., Hugo, H., Hunichen, J., \& Welte, D. (2020). Navigating the New Era of Influencer Marketing: How to be Successful on Instagram, TikTok, \& Co. California Management Review, 63(1), 5-25.

Ham, C. D., Lee, J., Hayes, J. L., \& Bae, Y. H. (2019). Exploring sharing behaviors across social media platforms. International Journal of Market Research, 61(2), 157-177.

Hamblin, J. (2019, March 20). Woke Wellness: An Industry Moves Beyond Vitamins and Tonics. The Atlantic. https://www.theatlantic.com/health/archive/2018/11/wellspring-festivalwoke-wellness/576103/ 
Highfield, T. and Leaver, T. (2014), “A methodology for mapping instagram hashtags”, First Monday(Peer-Reviewed Online Journal), Vol. 20 No. 1, http://firstmonday.org/ojs/index.php/fm/article/view/5563/4195

Jenke, T. (2020, September 3). Vulnerability Porn: The Latest Trend Sweeping Social Media. Rolling Stone Australia. https://au.rollingstone.com/culture/culture-features/vulnerabilityporn-latest-trend-social-media-16532/

Jensen Schau, H., \& Gilly, M. C. (2003). We are what we post? Self-presentation in personal web space. Journal of consumer research, 30(3), 385-404.

La Ferla, R. (2019, March 28). The Captionfluencers. The New York Times. https://www.nytimes.com/2019/03/27/style/instagram-long-captions.html

Lieberman, C. (2018, August 10). How Self-Care Became So Much Work. Harvard Business Review. https://hbr.org/2018/08/how-self-care-became-so-much-work

Lorenz, T. (2019, April 24). Influencers Are Abandoning the Instagram Look. The Atlantic. https://www.theatlantic.com/technology/archive/2019/04/influencers-are-abandoninginstagram-look/587803/

Mayring, P. (2004), “Qualitative Content Analysis”, in Flick, U., Von Kardoff, E. \& Steinke, I. (Eds), A Companion to Qualitative Research, Sage Publications, 266-269.

McMahon, D. M. (2006). Happiness: A history. Grove Press.

Miller, J. W. (2005). Wellness: The history and development of a concept. Spektrum Freizeit, 25(1), 95-104 
Miller, M., \& Levine, T. (2019). Persuasion. In D. Stacks, M. Salwen, \& K. Eichhorn (Eds.), An Integrated Approach to Consumer Theory and Research (3rd ed., pp. 261-275). Taylor \& Francis. https://doi.org/10.4324/9780203710753

Mintel. (2020a, March). Internet Influencers. https://data-mintelcom.proxy.mul.missouri.edu/databook/986902/question/Q6Net/group/2?country=3\&d=g $\underline{\text { ender } \& d=\text { age } \& \text { presentation }=\text { graphs }}$

Mintel. (2020b, April). Global Consumer Trends 2030.

Mintel. (2020c, May). Marketing to Gen Z: Incl Impact of Covid-19. https://reports-mintelcom.proxy.mul.missouri.edu/display/986950/?fromSearch=\%3Ffreetext\%3Dmarketing\% 2520 to $\% 2520$ gen $\% 2520 \mathrm{z}$

MOJO Ad. (2019, December). Decoded: State of the YAYA. https://issuu.com/mojoadvertising/docs/state_of_the_yaya_2019_pages

Mudambi, S., \& Schuff, D. (2010). Research Note: What Makes a Helpful Online Review? A Study of Customer Reviews on Amazon.com. MIS Quarterly, 34(1), 185-200. doi: $10.2307 / 20721420$

National Geographic Society. (2019, August 19). Chinese Religions and Philosophies. https://www.nationalgeographic.org/article/chinese-religions-and-philosophies/

Neuendorf, K. A., \& Kumar, A. (2015). Content analysis. The international encyclopedia of political communication, 1-10.

RPA. (2018). Identity Shifters: A Gen Z Exploration. Rubin Postaer and Associates. 
Schwab, D. (2016, May 11). Why Lifestyle Influencers Are The Next "It” Endorser. Forbes. https://www.forbes.com/sites/davidschwab/2016/05/11/why-lifestyle-influencers-are-thenext-it-endorser/\#37e913a3524f

Sehl, K. (2020, November 18). The Complete Guide to Instagram Influencer Rates in 2020. Social Media Marketing \& Management Dashboard. https://blog.hootsuite.com/instagram-influencer-rates/

Sengupta, J., Dahl, D. W., \& Gorn, G. J. (2002). Misrepresentation in the consumer context. Journal of Consumer Psychology, 12(2), 69-79.

Sokolova, K., \& Kefi, H. (2020). Instagram and YouTube bloggers promote it, why should I buy? How credibility and parasocial interaction influence purchase intentions. Journal of Retailing and Consumer Services, 53.

Sweet, J. (2018, October 28). “The Spirit Almanac” Uses Ancient Rituals To Reveal Magic In Modern Life. Forbes. https://www.forbes.com/sites/jonisweet/2018/10/28/new-wellnessbook-on-ancient-rituals/?sh=531c80596711

Sweetser, K. D., \& Keshelashvili, A. (2005). Examining the New Influencers: A SelfPresentation Study of A-List Blogs. Journalism \& Mass Communication Quarterly, 82(4), 968-982. https://doi.org/10.1177/107769900508200413

Tafesse, W., \& Wood, B. P. (2020). Followers' engagement with instagram influencers: The role of influencers' content and engagement strategy. Journal of Retailing and Consumer Services, 58, 102303. 
Thorson, E., \& Rodgers, S. (2019). Advertising. In D. Stacks, M. Salwen, \& K. Eichhorn (Eds.), An Integrated Approach to Communication Theory and Research (3rd ed., pp. 199-210). Taylor \& Francis. https://doi.org/10.4324/9780203710753

Tracy, S. J. (2020). Qualitative research methods: Collecting evidence, crafting analysis, communicating impact (2nd ed.). Wiley-Blackwell.

Tran, T. (2020, July 28). Instagram Demographics That Matter to Social Media Marketers in 2020. Social Media Marketing \& Management Dashboard. https://blog.hootsuite.com/instagramdemographics/\#:\%7E:text=Instagram\%20general\%20demographics\&text=30\%20million \%20users\%20in\%202012, updated\%20by\%20Instagram\%20in\%202017)

Veenhoven, R. (2019). Will Healthy Eating Make You Happier? A research synthesis using an online findings archive. Applied Research in Quality of Life, 1-20.

Vendemia, M. A., \& DeAndrea, D. C. (2018). The effects of viewing thin, sexualized selfies on Instagram: Investigating the role of image source and awareness of photo editing practices. Body image, 27, 118-127.

Welbourne, D.J. \& Grant, W.J. (2016). Science communication on youtube: factors that affect channel and video popularity. Public Underst. Sci. 25 (6), 706-718 (pMID:25698225).

World Advertising Research Center. (2020, February). What We Know About Health and Wellness Marketing. Ascential.

Wolkoff, J. (2020, March 3). How ancient Egyptian cosmetics influenced our beauty rituals. CNN. https://edition.cnn.com/style/article/ancient-egypt-beauty-ritual-artsy/index.html 